
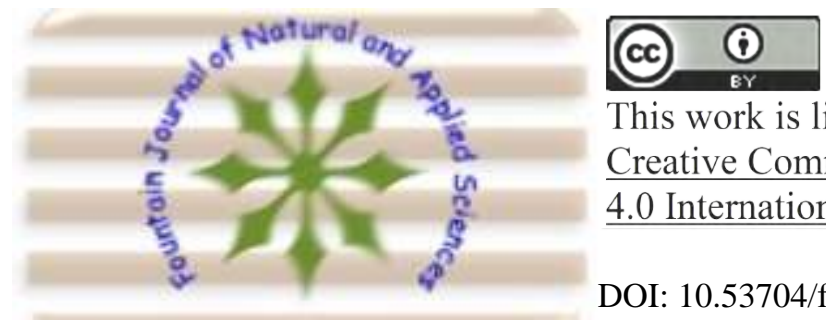

This work is licensed under

Creative Commons Attribution

4.0 International License.

DOI: $10.53704 /$ fujnas.v8i2.336

A publication of College of Natural and Applied Sciences, Fountain University, Osogbo, Nigeria.

Journal homepage: www.fountainjournals.com

ISSN: 2354-337X(Online),2350-1863(Print)

\title{
Progress in Carbon Nanotube-Based Electrochemical Biosensors - A Review
}

\author{
${ }^{* 1}$ Lawal, A. T., ${ }^{2}$ Bolarinwa, H. S., ${ }^{1}$ Adeoye, M. D., ${ }^{1}$ Abdulsalami, I. O., ${ }^{2}$ Animasahun, L. O. \\ and ${ }^{1}$ Alabi, K. A. \\ ${ }^{I}$ Department of Chemical Sciences, Fountain University, Osogbo, Nigeria \\ ${ }^{2}$ Department of Physics, Electronics and Earth Science, Fountain University Osogbo, Nigeria
}

\begin{abstract}
The use of carbon nanotubes (CNT) for fabrication of sensors and biosensors has increased considerably over the past decade. This review covers the progress and advances made during the years (2014-2018) in the utilisation of carbon nanotubes for fabrication of electrochemical biosensors. The focus of the review is on reported CNT-based biosensors for detection of, important substances, such as glucose, $\mathrm{H}_{2} \mathrm{O}_{2}$, (DNA), ascorbic acid, uric acid, dopamine, metal ions, and pesticides. The review starts by first discussing the structures and properties of CNTs, followed by discussion of some of the synthetic methods for CNTs preparation. The working principles and performances of CNT-based biosensors are then discussed. Considerations for future developments in CNT-based biosensors are also outlined.
\end{abstract}

Keywords: Biosensors, Carbon nanotube, Functionalisation, Glucose, Nanomaterials

\section{Introduction}

Biosensors are increasingly becoming a critical part of modern life, because these devices can be used for a diverse range of applications, ranging from diagnosis of life-threatening diseases (Son, Kim et al., 2016; Caglayan, 2017; Chen et al., 2017; Han et al., 2017; Pan et al., 2017; Syedmoradi et al. 2017; Thapa, et al., 2017; Wang et al., 2017; Wang, et al., 2017) to detection of biological agents in warfare or terrorist attacks (Bahadır \& Sezgintürk 2015). Recently, materials science has boosted the advances in the development of biosensors and has attracted huge interest due to its ability to greatly enhance biosensors performances and applications by incorporation of various nanomaterials (Campuzano et al., 2017; Hasanzadeh et al., 2017; Liu et al., 2017; Medyantseva et al., 2017; Reshetilov et al., 2017; Syedmoradi et al., 2017; Wang et al., 2017; Zhang \& Chen 2017; Zhang et al., 2017). Rapid and intense advances in the field of materials science have led to the synthesis of many new nanomaterials with unique physicochemical properties and these have driven the rapidly growing developments in nanomaterialbased electrochemical biosensors.

Among the various nanomaterials that have been synthesised and used to date, carbon-based nanomaterials such as CNTs (Lawal, 2016; Wahab et al. 2016; Dervisevic et al., 2017; Yang \& Shimizu 2017; Dervisevic et al., 2018), graphene (Cui et al., 2017; Terse-Thakoor et al., 2017; Xu et al., 2017; Yardim et al., 2017; Zhang et al., 2017; Zhu et al., 2017; Lawal 2018), buckypaper (Papa et al., 2014, Chatterjee et al., 2015) and nanohybrids (Gu et al., 2016, Ko et al., 2017; Shuai et al., 2017, Wang et al., 2017) have attracted enormous

*Corresponding author: +2348131826098

Email address: abdul.lawal@yahoo.com 
attention due to their widely recognised application to chemical and biochemical sensors which have led to the increasing use for the electrochemical sensing of various compounds (Bai et al., 2016; Hamidi \& Haghighi, 2016; Pandey et al., 2016; Saxena \& Das 2016; Wu et al., 2016; Xu et al., 2016; Wu et al., 2017; Yang et al., 2017, Yang et al., 2017; Zhao et al., 2017; Zhou et al., 2017).

Carbon based nanomaterials have received special attention because of their remarkable mechanical and electrical properties. These nanomaterials offer diverse advantages due to their unique properties, such as a high surface-to-volume ratio, high electrical conductivity, chemical stability, biocompatibility, and robust mechanical strength. Carbon-based nanomaterials have been found to be advantageous for construction of electrochemical biosensors because they increase the electroactive surface area, enhance electron transfer, and promote adsorption of molecules (Tiwari et al., 2016; Wang et al., 2016; Zhang \& Yuan 2016; Jaiswal \& Tiwari 2017). CNTs are one of the most innovative nanomaterials because of their exceptional physical, chemical, and electrical characteristics, which offer unique electronic, optical, mechanical, thermal, chemical and electrochemical properties (Soleymani 2015). CNTs also offer a large edge plane/basal plane ratio, and rapid electrode kinetics. Therefore, there has been a considerable progress in recent years in the synthesis and use of single and multi-walled carbon nanotubes (CNTs) for the design and construction of novel biosensor (Luo et al., 2017; Sharma et al., 2017; Wu et al., 2017). The use of CNTs offers to the biosensing platforms exceptional optical, electronic and magnetic properties. These nanomaterials are capable of increasing the surface area of the chosen transducer for the sensors and, in turn, results in substantial increase in catalytic and sensor performances. CNTs have been used in construction of biosensors which operated in various transduction modes, ranging from electrical and electrochemical to optical detection (Zhu \& Lee, 2017). Their excellent fluorescence quenching ability has been exploited in optical sensors (Jain et al., 2015; Kim et al., 2015, Budhathoki-Uprety et al., 2017). Among the exceptional properties of CNTs, its large surface area, high electrical conductivity and their very efficient electrocatalytic behaviour are the most relevant for electrochemical applications. Therefore, CNT-based biosensors generally achieve higher sensitivities, lower limits of detection, and faster electron transfer kinetics than traditional carbon electrodes. Other utilisation of CNTs for fabrication of sensors, include uses for chemical sensors (Wang et al., 2017), gas sensors (Chen et al., 2017; Żelechowska et al., 2017), mechanical sensors, resonant sensors, humidity sensors, biofuel cells (Bandodkar et al., 2016; Ouyang et al., 2016; Shoji et al., 2016; Shu et al., 2016; Qu et al., 2017), environment sensors (Arduini et al., 2016; Piro et al., 2016; Ramnani et al., 2016) and optical sensors (Jain et al., 2015; Kim et al., 2015).

Due to the unique properties of electroanalytical techniques, CNTs have received enormous attention for construction of electrochemical sensors and biosensors (Uwimbabazi et al., 2017; Yoo et al., 2017). Different electroanalytical techniques have been employed for the development of CNTs electrochemical biosensors for the detection and quantification of many biomolecular species (Dervisevic et al., 2017; Uwimbabazi et al., 2017; Yang et al., 2017), chemical compounds, inorganic ions in environmental and biological samples (Braga et al., 2015; Cui et al., 2015). Various CNTs electrochemical biosensors have been developed for detecting and quantification of medically and pharmaceutically important compounds such as glucose (Shrestha et al., 2016; Song et al., 2017; Surucu \& Abaci, 2017; Termehyousefi et al., 2017, Uwimbabazi et al., 2017; Zhou et al., 2017; Jiang et al., 2018), acetaminophen (Alam et al., 2018), methylglyoxal, $\mathrm{H}_{2} \mathrm{O}_{2}$ (Hamidi \& Haghighi, 2016; Dramińska \& Bilewicz, 2017; Sánchez-Tirado et al., 2017), metal ions (Moyo et al., 2014a; Shi et al., 2017; Somayeh, et al., 2017), DNA (Fu et al., 2017; Hien et al., 2017; Huang et al., 2017) (Chiorcea-Paquim, et al., 2017; Unal et al., 2017), ascorbic acid (Deb et al., 2016; Hu et al., 2016), uric acid (Erden et al., 2015; Ghodsi et al., 2015; Sun et al., 2015; Hu et al., 2016; Yang et al., 2016), Nicotinamide Adenine Dinucleotide (NADH) (Eguílaz, Gutierrez et al., 2016; Mutyala \& 
Mathiyarasu 2016; Atta et al., 2017), acetaminophen (Cernat et al., 2015; Moretti et al., 2016), herbicides (Szabó et al., 2017) and pesticides (Zhang et al., 2015; Zhang et al., 2015; Liu et al., 2016; Miao et al., 2016) .

Biomolecular detection with CNT-based biosensors has attracted considerable applications in many areas of health care, screening of new drug molecules (Karimi-Maleh et al., 2016; Yue et al., 2016), HIV screening (Ma et al., 2017), cardiac biomarker (Prakash et al., 2017), malaria biomarker (Paul et al., 2017), clinical medicine (Janegitz et al., 2014; Revathi et al., 2015; Zribi et al., 2016), pharmaceutical products (Adhikari et al., 2015; Alpat et al., 2016; Koteshwara et al., 2017), food safety (Abdalhai et al., 2015; Zeng, et al., 2016; Kitikul et al., 2017) and environmental monitoring (Kim et al., 2016). The high surface- to -volume ratio of CNTs makes it possible to obtain ultrafast detection of biomolecular species at low temperature. CNTs-based biosensors are ultrasensitive, have fast response time, lower redox reaction potentials and less fouling effect. These devices have high stability and longer life than the commercial metal oxide, silicon and other material sensors (Sharma et al., 2017). These enhanced characteristics have stimulated a lot of research interest in utilisation of CNTs as components for electrochemical biosensors. The advantages of CNT-based electrochemical biosensors include: (i) high sensitivity due to the large surface area ratio and hollow pipe which enables immobilisation of enzyme or other biomolecules to maintain a high biological activity; (ii) fast response time due to the outstanding ability of CNTs to mediate fast electron-transfer kinetics and, hence, promote electron-transfer reactions like $\mathrm{NADH}$ and $\mathrm{H}_{2} \mathrm{O}_{2}$; (iii) lower potential of redox reaction and less surface fouling effects; and (iv) high stability and longer lifetimes.

Two types of CNTs are commonly used for fabrication of biosensors. As these carbon nanomaterials may comprise of either a single graphitic layer, or multiple coaxial layers, they result in the formation of two distinct types of CNTs: (a) single-walled carbon nanotubes (SWCNTs) and (b) multiple-walled carbon nanotubes (MWCNTs) (Yang et al., 2015). SWNTs consist of a single graphite sheet seamlessly wrapped into cylindrical tubes, having diameters of between $0.4 \mathrm{~nm}$ and $2.5 \mathrm{~nm}$ (Fig.1b), while MWCNT is composed of more than two layers of curly graphite sheet, and its diameter is at the range of 2-30 nm and some even more than $100 \mathrm{~nm}$ (Fig. 1b), the distance between each layer is approximately $0.42 \mathrm{~nm}$. MWCNT have shown the most promising appearance to the market place in recent times. Both SWCN and MWCNT equally used as electrode materials. The small size of SWCN and a corresponding large active surface area of MWCNT, the easy functionalisation with carboxyl or amino were the advantages, which were exploited by CNT for electrochemical applications.

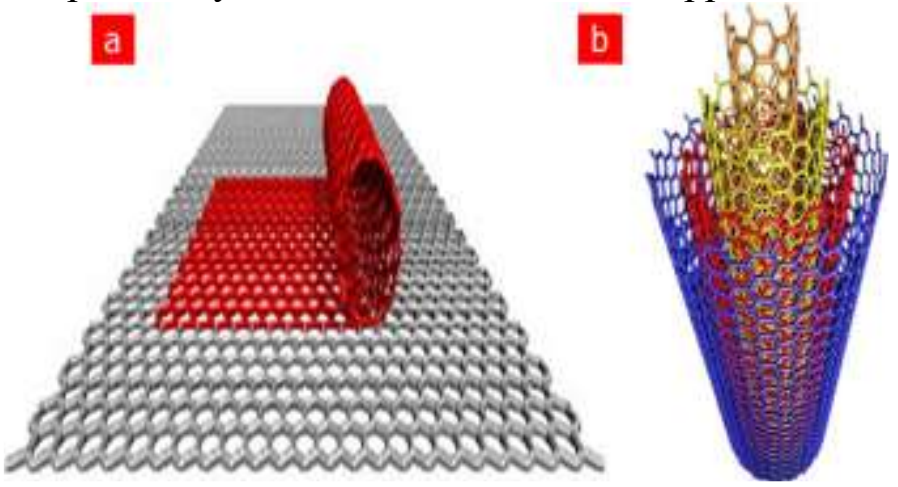

Figure 1: (a) Schematics of SWCNTs which composed of a single layer of curly graphite.

(b) Schematics of MWCNTs. (Yang et al. 2015)

\section{Scope of this Review}

This review highlights recent progress made in the utilisation of CNTs for fabrication of electrochemical biosensors. Considering the numerous reports and reviews (Malhotra et al., 2014; Sagadevan \& Periasamy, 2014, Tiwari \& Turner 2014; Barsan, et al., 2015; Soleymani, 2015; Yang et al., 2015; Yang et al., 2015; Barsan \& Brett 2016; Lawal, 2016; Shanta et al., 2017; Zhu, 2017, Gupta et al., 2018) that have been published on CNT-based biosensors, this review has been limited to the recent progress made in the years (2014-18) on the utilisation of CNTs for fabrication of electrochemical biosensors. More specifically, this review considers three aspects of the utilisation of CNTs for construction of CNTs-based enzymatic, CNTs-based non-enzymatic and CNTs-based nanoelectronic devices. For the CNT-based enzyme biosensor, the focus will be on the electrochemical 
detection of glucose, NADH, and cholesterol. For CNTs-based non-enzymatic electrodes, the detection of glucose, $\mathrm{H}_{2} \mathrm{O}_{2}$, Ascobic acid (AA), Uric Acid (UA) and Dopamine (DA) will be considered. Lastly, the CNT-based nano-electronic devices will focus on detection of DNA, organophosphate compounds and heavy metal ions.

\section{Synthesis and Functionalisation of CNTs Synthesis}

The increase in momentum in research on CNTs has resulted in the high demand of CNTs in industry and recently it is becoming increasingly urgent in demand. There are three basic methods for synthesis of SWCNTs and MWCNTs: electrical arch discharge, laser ablation (laser vaporization) and chemical vapour deposition (CVD) (or catalytic decomposition of hydrocarbons). Research on CNTs is more and more extensively pursued and the synthetic methods of CNTs have been improved. In arc discharge the current through two graphite electrodes creates a deposit of CNTs on the cathode. By altering conditions either SWCNTs or MWCNTs can be synthesised. Laser vaporization of graphite in a silica tube lined, high temperature furnace generally results in MWCNTs, but with the use of catalytic metal nanoparticles, SWCNTs can be synthesised. MWCNTs are produced by CVD during the pyrolysis of hydrocarbon gases at high temperatures. Table 1 shows the lists of various methods for preparing various kinds of CNTs in recent years.

\section{Functionalisation}

CNTs have poor solubility in most solvents and this limits their applications. The outer walls of pristine CNTs are chemically inert. CNTs are required to functionalise in order to provide biocompatibility and solubility. Functionalisation of CNTs with other functional materials, such as enzyme, proteins or nanomaterials, is a rational way to regulate their properties to fulfil different biosensing requirements. Noncovalent and covalent surface functionalisations are two commonly used methodologies to modify CNTs. Their poor solubility in aqueous and organic solvents and limited compatibility with polymer matrices are major drawbacks, rendering these materials incapable of achieving their full potential. Consequently the functionalisation of nanotubes is extremely important, as it increases their solubility and process ability. Functional CNTs have attracted much attention for analytical and biomedical applications. Functionalisations of CNTs can be achieved by physical and chemical methods. CNTs can be functionalised with different chemical groups using covalent and non-covalent procedures which will enhance and enrich their functions in electrochemical biosensors. Most of the current functionalisation methods follow covalent or chemical approach. Through this method, a strong covalent bonding is formed between CNTs and coupling agent.

Physical methods includes the mechanical means such as ultrasonic, milling, crushing and friction to activate CNTs surface to change their surface physical and chemical structure. This method increase CNTs' internal energy and surface activity and then make the tubes react with or attached to other materials, to attain the purpose of the surface modification. At present, the large shear force or ultrasonic processing is often used to disperse CNTs. Some other physical surface modifications include ultraviolet, plasma beam, electron beam, high-energy corona discharge and $\mu$-ray.

Chemical methods mainly have two approaches: covalent modification (Emami \& Haghjoo, 2014, Eguílaz et al., 2016a, Eguílaz et al., 2016b, Bensghaïer et al., 2017; Costa, et al., 2017, Dagar \& Pundir 2017) and non-covalent modification ( Eguílaz et al., 2016c; Kangkamano et al., 2017) (Figs.2 and 3). Non covalent modification can retain the original structure and properties of CNTs, and does not damage the system while the structure of covalent modification is more stable. In Noncovalent modification, the highly delocalised electron via $\mathrm{sp} 2$ hybridization of carbon atoms in CNTs can be combined with other compounds containing Pie electrons through the Pie-Pie noncovalent bonding effect. Non-covalent bond is much weaker than covalent bonding. Non-covalent modification generally uses conjugated polymers, bioactive molecules (e.g. DNA, enzyme, protein) 
Table 1: The synthetic methods of CNTs.(Yang, Chen et al. 2015)

\begin{tabular}{|c|c|c|c|}
\hline Method & Progress & Consequence & Refs. \\
\hline \multirow[t]{5}{*}{ Arc discharge } & $\begin{array}{l}\text { Synthesized between two } \\
\text { graphite rods in water bath at } \\
\text { different voltage }\end{array}$ & $\begin{array}{l}\text { Good quality and high yield } \\
\text { CNTs are obtained }\end{array}$ & $\begin{array}{l}\text { (Lakshmi and } \\
\text { Khan 2014) }\end{array}$ \\
\hline & $\begin{array}{l}\text { Two graphite electrodes } \\
\text { submerged in different liquid } \\
\text { media }\end{array}$ & $\begin{array}{l}\text { Yielding various dimensional } \\
\text { nanocarbon structures }\end{array}$ & \\
\hline & $\begin{array}{l}\text { Using strong oxidizing agent } \\
\mathrm{HNO}_{3} / \mathrm{H}_{2} \mathrm{O}_{2} \text { instead of metal } \\
\text { catalyst and vacuum devices }\end{array}$ & Improving purity of MWCNTs & \\
\hline & $\begin{array}{l}\text { The discharge is maintained in a } \\
\text { magnetic field }\end{array}$ & $\begin{array}{l}\text { High quality MWCNTs are } \\
\text { obtained }\end{array}$ & \\
\hline & $\begin{array}{l}\text { Using physical forces both during } \\
\text { synthesis }\end{array}$ & $\begin{array}{l}\text { Relatively straight and defect } \\
\text { free MWCNTs are obtained }\end{array}$ & \\
\hline \multirow[t]{5}{*}{ Laser ablation } & $\begin{array}{l}\text { Dynamic light scattering, micro- } \\
\text { Raman and high-resolution } \\
\text { transmission electron microscopy } \\
\text { were used }\end{array}$ & $\begin{array}{l}\text { Controlling } \\
\text { nanostructures }\end{array}$ & \\
\hline & $\begin{array}{l}\text { Using binary catalysts combining } \\
\text { the transition metals } \mathrm{Fe}, \mathrm{Co} \text { and } \\
\mathrm{Ni}\end{array}$ & $\begin{array}{l}\text { Different carbon } \\
\text { nanostructures can be obtained }\end{array}$ & \\
\hline & $\begin{array}{l}\text { Direct synthesis using pulsed } \\
\text { laser ablation }\end{array}$ & $\begin{array}{l}\text { SWCNTs show fast and strong } \\
\text { photo-response (as high as } \\
1350 \% \text { at } 405 \mathrm{~nm})\end{array}$ & \\
\hline & $\begin{array}{l}\text { Irradiating of a } \mathrm{CO} 2 \text { laser in } \\
\text { continuous wave mode onto a } \\
\text { boron-containing graphite target } \\
\text { at room temperature }\end{array}$ & $\begin{array}{l}\text { The fine crystalline structure of } \\
\text { MWCNTs can be obtained }\end{array}$ & \\
\hline & $\begin{array}{l}\text { Ablating a nickel/carbon } \\
\text { composite target in ethanol or } \\
\text { ambient air }\end{array}$ & MWCNTs & \\
\hline \multirow[t]{3}{*}{ CVD } & $\begin{array}{l}\text { Growing on iron catalyst film } \\
\text { using plasma enhanced chemical } \\
\text { vapour deposition (PECVD) } \\
\text { system }\end{array}$ & $\begin{array}{l}\text { Vertically aligned single wall } \\
\text { carbon nanotubes of diameter } \\
0.8-1.5 \mathrm{~nm} \text { can be obtained }\end{array}$ & $\begin{array}{l}\text { (Ali, Kumar et } \\
\text { al. 2014) }\end{array}$ \\
\hline & $\begin{array}{l}\text { Co was used as catalysts, at } 700 \\
{ }^{\circ} \mathrm{C} \text { using hydrogen to acetylene } \\
\text { gas ratio at } 25: 25 \mathrm{Sccm}\end{array}$ & High yield of MWCNTs & \\
\hline & $\begin{array}{l}\text { Using } \mathrm{NiO} \text { powder as catalysts } \\
\text { and LPG as carbon source }\end{array}$ & The yield of CNTs increased & \\
\hline
\end{tabular}




\begin{tabular}{|c|c|c|c|}
\hline & AlPO4 was used as catalysts & Y-shaped CNTs & \\
\hline & $\begin{array}{l}\text { Taking iron nanoparticles as } \\
\text { catalyst }\end{array}$ & SWCNTs & \\
\hline & $\begin{array}{l}\text { Taking Co-Mo as catalyst and } \\
\text { using } \mathrm{CH} 4 \text { at } \\
900{ }^{\circ} \mathrm{C}\end{array}$ & SWCNTs & \\
\hline & Metal catalyst-free mist flow & $\begin{array}{l}\text { SWCNTs can be synthesized } \\
\text { without any treatments }\end{array}$ & $\begin{array}{l}\text { (Fu, Cui et al. } \\
2014)\end{array}$ \\
\hline & $\begin{array}{l}\mathrm{Ni} \text { over } \mathrm{Cr} \text { layer as a catalyst at } \\
600^{\circ} \mathrm{C}\end{array}$ & CNTs & \\
\hline & $\begin{array}{l}\text { Taking } \mathrm{Ni} / \mathrm{MgO} \text { as catalyst and } \\
\text { using } \mathrm{CH} 4 \text { in micro-fluidized bed }\end{array}$ & $\begin{array}{l}\text { CNTs exhibited relatively } \\
\text { small and mean outer diameter, } \\
\text { less defect, and high purity }\end{array}$ & $\begin{array}{l}\text { (Fu, Cui et al. } \\
2014)\end{array}$ \\
\hline & Photochemical deposition & MWCNTs & \\
\hline $\begin{array}{l}\text { Low- } \\
\text { temperature } \\
\text { plasma }\end{array}$ & $\begin{array}{l}\text { The plasma causes the } \\
\text { dissociation of carbon resource }\end{array}$ & $\begin{array}{l}\text { CNTs with highly distributed } \\
\text { active species and catalyst } \\
\text { activation }\end{array}$ & \\
\hline $\begin{array}{l}\text { Low- } \\
\text { temperature } \\
\text { plasma } \\
\text { reduction }\end{array}$ & $\begin{array}{l}\text { Facile glow discharge plasma } \\
\text { reduction operated at room } \\
\text { temperature }\end{array}$ & CNTs & \\
\hline Solvothermal & At the low temperature of $180{ }^{\circ} \mathrm{C}$ & MWCNTs bundles & \\
\hline $\begin{array}{l}\text { Low- } \\
\text { temperature } \\
\text { solvothermal }\end{array}$ & $\begin{array}{l}\text { Dichlorobenzene as a carbon } \\
\text { source was catalyze by a } \\
\text { solvothermal approach at } 200^{\circ} \mathrm{C}\end{array}$ & $\begin{array}{l}\text { Well-aggregated carbon } \\
\text { nanotubes are achieved }\end{array}$ & \\
\hline Solvothermal & $\begin{array}{l}\text { At the temperature of } 200^{\circ} \mathrm{C} \text { and } \\
\text { a reaction for } 10 \mathrm{~h}\end{array}$ & $\begin{array}{l}\text { Magnetic MMWCNTs with } \\
\text { alterable structure }\end{array}$ & \\
\hline Sol-gel & $\begin{array}{l}\text { The mixed solution was } \\
\text { evaporated at } 80{ }^{\circ} \mathrm{C} \text { for } 8 \mathrm{~h}\end{array}$ & MWCNT-LiMn2O4 & \\
\hline
\end{tabular}

and conjugated polycyclic aromatic hydrocarbons (e.g. pyrene and its derivatives) to disperse and functionalise CNTs. Proteins are often used material to disperse CNTs efficiently in aqueous medium. Covalent modification occurs in tip defects as well as side wall of CNTs. The principle of the method is that the CNTs are first oxidised by high concentration acid and this is followed by introducing functional groups (e.g. carboxyl) onto in the terminal or the defect sites of lateral wall of CNTs. Therefore, CNTs can be functionalised with different functionalities by covalent modification to meet the different requirements of biosensing applications. Covalent modification in tip mainly includes carboxylation and subsequent derivatisation, such as amidation and esterification reaction (Fig. 2). But in covalent modification in side wall includes fluorination, alkylation reaction, cycloaddition which can improve the properties of CNTs and to a certain extent it will destroy the sp2 structure of the CNTs there by influencing their 
stability. Covalent modification of CNTs is much more desirable when stronger interaction

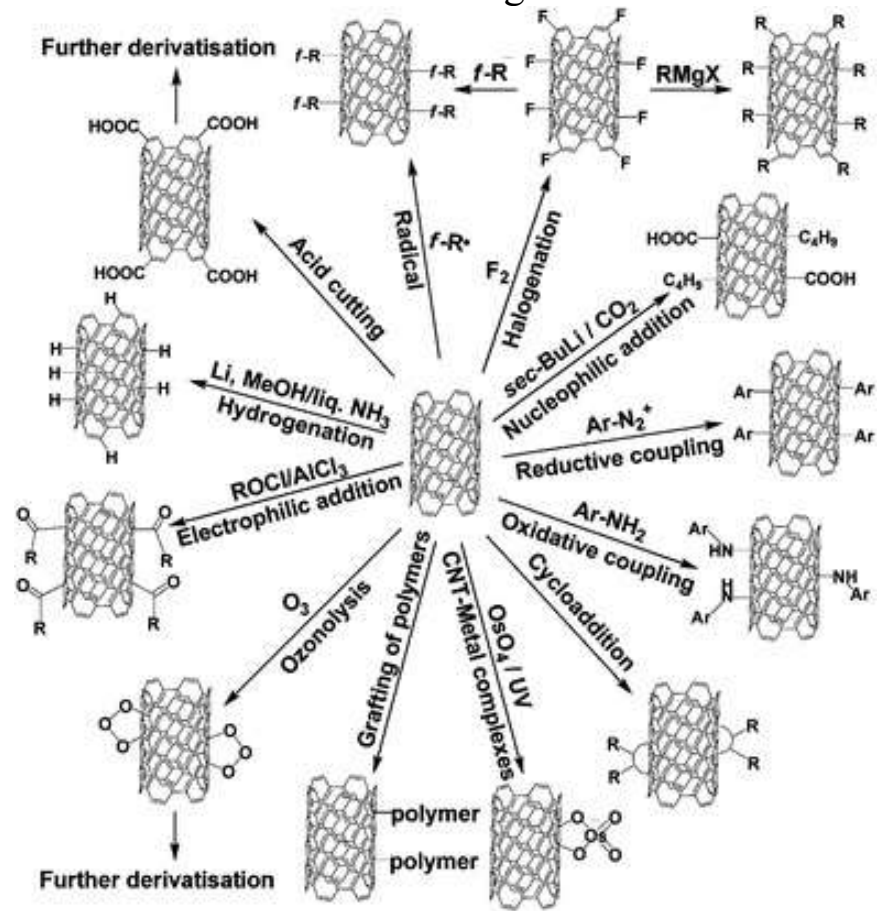

Figure 2: Covalent functionalisation (Yang et al., 2005).

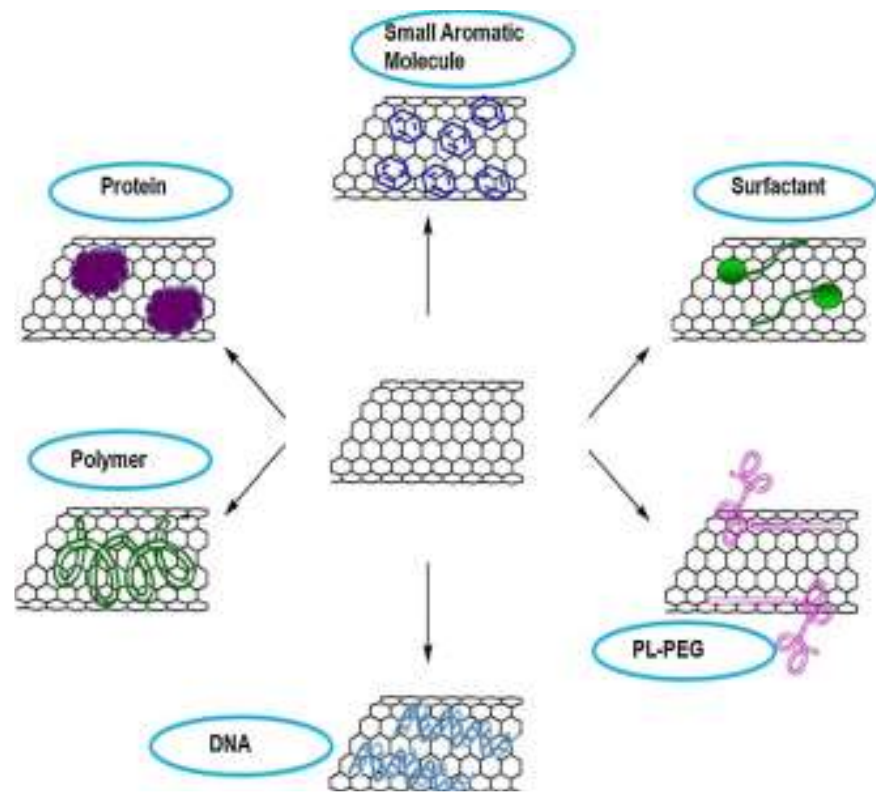

Figure 3: Functionalization of CNTs with various nanomaterials (Yang et al., 2015)

between CNTs and the modifier is required. comparing with adsorption enzymes, covalently immobilized enzymes are combined closely with carrier, thus have high stability and repetition of usability.

\section{Working principles of CNT-based biosensors}

Biosensors are integrated receptor-transducer devices capable of providing selective quantitative or semi quantitative analytical information using a biological recognition element. Majority of the biosensors developed till dates are based on electrochemical sensors that contain reference electrode, working electrode and a counter electrode. CNTs have been recognised a very prominent material for enhancing electron transfer which make them suitable for integration into electrochemical biosensors (Jain et al., 2015). An electrochemical biosensor is an analytical device in which a recognition element is integrated within or intimately associated with a signal transducer (an electrode) that converts the recognition event to a measurable electrical signal for the purpose of detecting a target analyte. Namely, electrochemical biosensors are based on the detection of electroactive species involved in chemical recognition processes and make use of charge transfer from a solid or liquid sample to an electrode or vice versa (Lawal, 2016).

The composition of CNTs biosensor includes two parts: biological sensitive element and the transducer. The CNT are sometimes functionalised with cell receptors, enzymes, antibodies, oligo or polynucleotides, microorganisms, or even whole biological tissues, and thereby working as the biological sensitive element (Fig. 4). The sol-gel derived materials are sometimes being used extensively to encapsulate enzymes, antibodies, microorganisms, and even whole cells (Xu et al., 2014; Hossain et al., 2015; Wu et al., 2015; Shoja et al., 2017). The role of transducer is to convert the concentration of analytes to other detectable physical signals, such as currents absorbance, mass or acoustic variables for testing and detecting. Biosensor has been defined as a device that consists of a highly selective and sensitive biological receptor element (e.g. tissue, micro-organisms, organelles, cell receptors, enzymes, antibodies, nucleic acids, etc.) intimately associated with a transducer element that translates the biological 
recognition process between the receptor and the analyte into a measurable signal (Fig. 4).

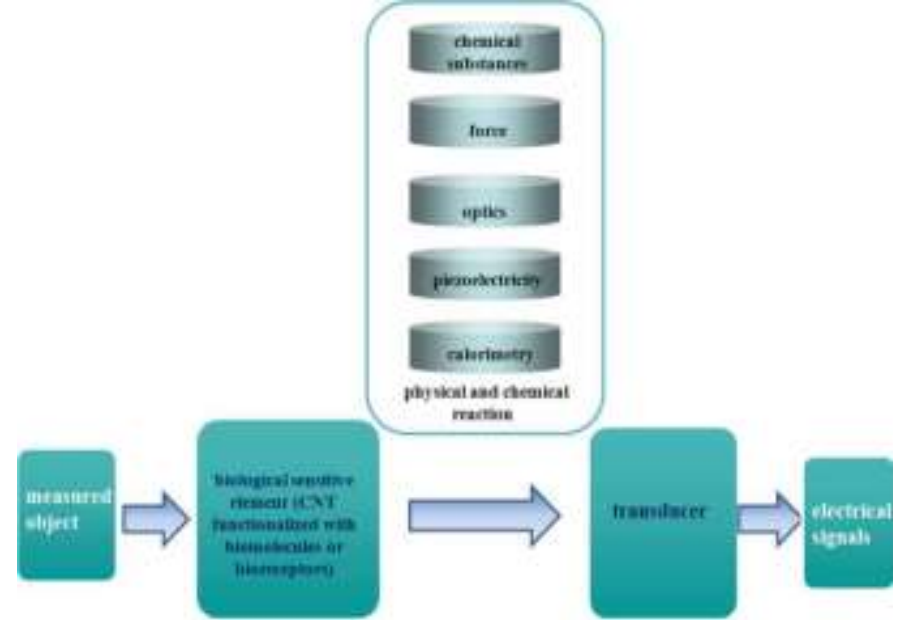

Figure 4: Schematic depiction of different CNTsbased biosensors. The physicalorchemical reaction is transformed into electrical signals after the target molecule was detected by detection device (Yang et al. 2015)

Electrochemical biosensors mainly have three types: amperometric-based, potentiometric-based and impedimetric-based, the amperometric-based mode is the most widely used. The sensing mechanism of amperometric CNTs-based biosensors is using the analytes, different enzymes are selected, such as NADH (Zhu, et al., 2014; Ertek \& Dilgin, 2016; Hamidi \& Haghighi, 2016; Lin et al., 2016; Mutyala \& Mathiyarasu, 2016; Atta et al., 2017), glucose oxidase (GOx) (Mansouri et al., 2017; Termehyousefi et al., 2017; Uwimbabazi et al., 2017; Zhou et al., 2017), aflatoxin-oxidase (Zhang et al., 2016; Costa et al., 2017), E. Coli (Yamada et al., 2014; Abdalhai et al., 2015; Guo et al., 2015; Ozkan-Ariksoysal et al., 2017), cholesterol oxidase (Gholivand \& Khodadadian, 2014; Ashby \& Ramasamy 2015; Shukla et al., 2015; Ahmadraji \& Killard, 2016; Pandey et al., 2016), urease (Emami \& Haghjoo 2014; Dagar \& Pundir, 2017; Dervisevic et al., 2018), lactic acid oxidase (Paga'n, et al., 2014; Meshram, et al., 2015), acetylcholinestterase (Chen et al., 2017) and horseradish peroxidase (Moyo et al., 2014b; Xu et al., 2015; Magyar et al., 2016). Oxidisable $\mathrm{H}_{2} \mathrm{O}_{2}$ or NADH is easily generated as a result of these enzymes, as described in equations (1) and (2):
Substrate $+\mathrm{O}_{2}$ Oxidase $\rightarrow$ Product $+\mathrm{H}_{2} \mathrm{O}_{2}$

Substrate + NADdehydeogenase $\rightarrow$ Product + NADH.

\section{Enzymatic Biosensor}

Enzymatic sensors play an important role in human daily life. Extensive studies of enzymatic sensors are focused on improving the activity, stability, and direct electrochemistry of enzymes. Enzymatic biosensors have been valuable bioanalytical devices for analysis of diverse targets in disease diagnosis (Singh et al., 2014), biological and biomedical research (Alshehri et al., 2016; Chandra, 2016).

Electrochemical biosensors based on the use of enzymes have received considerable attention since the first enzymatic electrode proposed by Clark and Lyons more than 40 years ago, due to the advantages of the association of the biocatalytic activity of enzymes with the high sensitivity and versatility of the electrochemical transduction. The enzyme immobilisation step is critical, since the biocatalyst has to remain active to perform an efficient biorecognition of the substrate and several methods have been used to immobilise these enzymes on CNTs and its composites (Fig.5). The other aspect to consider is that the transducer where the enzyme is immobilised has to allow a fast charge transfer to ensure a rapid and sensitive response. Several strategies for immobilising proteins on CNTs modified electrodes have been proposed, the ones involving noncovalent functionalisation of the sidewalls of SWCNTs being the best to preserve the $\mathrm{sp}^{2} \mathrm{CNT}$ structure and their electronic characteristics.

Electrochemistry of enzymes involves direct electron transfer (DET) between the electrode and the active centre of the enzymes without the participation of mediators or other reagents (Vilian \& Chen 2014; Yu et al., 2014; Sanzó et al., 2015; Luong et al., 2017; Muguruma et al., 2017, Xia et al., 2017) (Fig. 6). New mediator-free (or reagentless) biosensors, enzymatic bioreactors, and biomedical devices employ DET by immobilising enzymes on conducting substrates. But, the redox centres of the biomolecules are usually embedded deep in their large three dimensional structures. CNTs and metal nanoparticles have exhibited excellent performance in enhancing the DET between enzymes 


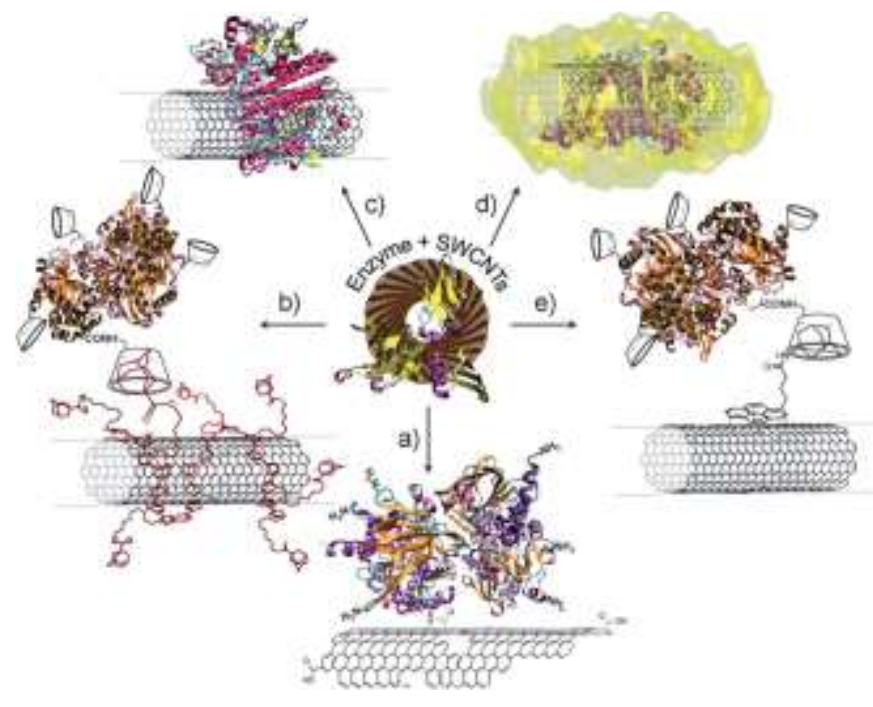

Figure 5: Immobilization strategies of enzymes on SWCNTs: (a) covalent binding via amide coupling with the carboxylic acid groups of oxidized nanotubes; (b) electrochemical coating of nanotubes with affinity partners and subsequent immobilization of affinity counterpart modified enzymes; (c) adsorption of enzymes on SWCNTs via hydrophobic or electrostatic interactions; (d) entrapment of enzymes in a polymer matrix formed around SWCNTs; and (e) immobilization via affinity interactions onto functionalized nanotubes (Yang et al. 2015).

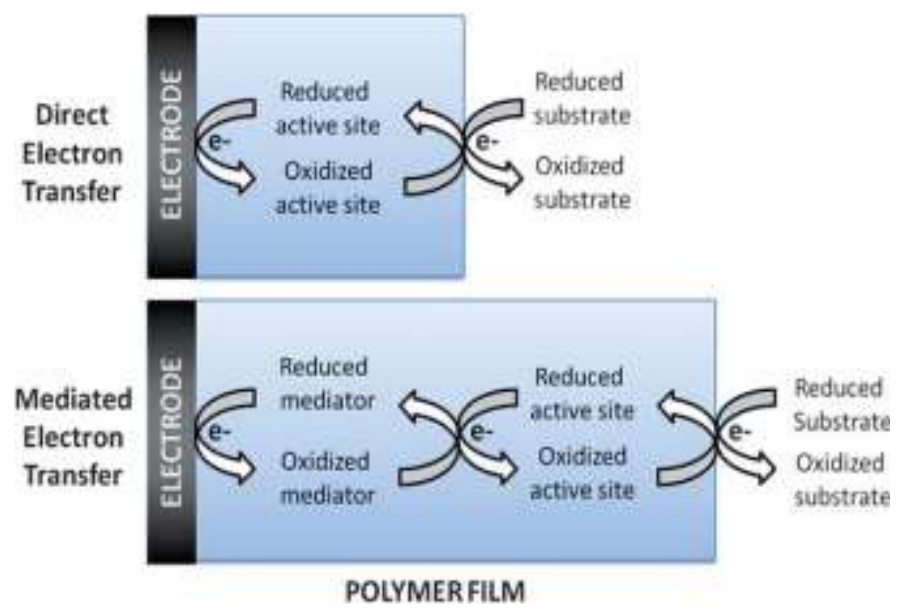

Figure 6: Anodic direct electron transfer and mediated electron transfer (Lawal, 2018).

Non enzymatic biosensor

and electrodes, and are now widely used. Recent research has shown that CNTs can enhance DET between enzymes and electrodes. DET was also evidenced at SWCNT electrodes for many redox proteins such as glucose, haemoglobin, Cytochrome C, microperoxidases and catalases (Figure 4).

Although several researchers have reported low detection limits and high accuracies in enzymatic biosensor, but there are several disadvantages of enzyme-modified electrodes, such as their instability, the high cost of enzymes and the complexity of immobilisation. Since, the activity of enzymes can be affected by temperature, $\mathrm{pH}$, and toxic chemicals; several researchers now pay considerable attention to nonenzymatic electrodes in attempts to eliminate above enzyme problems.

\section{Carbon Nanotube Nano Composites}

Hybrid composites based on CNTs with inorganic (Tak et al., 2016; Guzsvány et al., 2017; Kaçar et al., 2017; Narang et al., 2017; Paul et al., 2017; Sağlam \& Dilgin, 2017; Shiravand \& Azadbakht, 2017; Shoja et al., 2017; Song et al., 2017), conducting polymer (Li \& Lee 2015; Meiyazhagan et al., 2015; Meshram, 2015; Shrivastava et al., 2016; Ates et al., 2017; Jasim et al., 2017; Satyanarayana et al., 2017; Su et al., 2017; Vinay et al., 2017; Gui et al., 2018) and organic materials (Pereira et al., 2015; Rather et al., 2015; Thirumalraj et al., 2015; Vilian et al., 2015; Hien et al., 2017; Poo-Arporn, Pakapongpan et al. 2017; Savalia \& Chatterjee 2017; Thapa et al., 2017) have been reported in the recent times. Hybridisation of nanometals to carbon nanomaterials such as CNTs produces a synergistic effect on the electrocatalytic activity when compared to either material alone. These hybrid materials formed have shown great potential application in catalysis (Baghayeri \& Veisi 2015), electronics (Cavallini et al., 2015), optics and sensors (Barsan et al., 2015; Cernat et al., 2015, Zhao et al., 2015; Adhikari et al., 2017; Correa et al., 2017). CNT-inorganic nanocomposites (Braga et al., 2015; Cui et al., 2015; Narang et al., 2017; Sağlam \& Dilgin 2017) have opened up an exciting new field in the science and technology of CNT. CNT-metal nanoparticles have excellent conductivity and catalytic properties, which make them suitable for acting as 'electronic wires' to enhance the electron transfer between the redox centres in proteins and electrode surfaces, and as catalysts to increase electrochemical reaction rates 
(Li et al., 2015; Zhao et al., 2015; Dagar \& Pundir 2017; Dalkıran et al., 2017). Several biosensors have been developed using CNT-metal nanocomposite. The conductivity of nanocomposites enhances electron transfer between the active centres of enzymes and electrodes so that the particles act as electron transfer conduits or mediators (Luong et al., 2017; Muguruma et al., 2017, Termehyousefi et al., 2017; Eguílaz et al., 2016). Conductive polymer-CNT nanocomposites have improved the operational characteristics such as selectivity, stability, or sensitivity of the resulting biosensors (Shrivastava et al., 2016; Punetha et al., 2017).

\section{Carbon Nanotube-Based Enzymatic Electrodes}

Electrochemistry of enzymes involves direct DET between the electrode and the active centre of the enzymes without the participation of mediators or reagent (reagentless). Reagentless biosensors, enzymatic bioreactors, and biomedical devices are such that employ DET by immobilising enzymes on conducting substrates. However, the redox centres of the biomolecules are usually embedded deep in their large three dimensional structures. Recent research has shown that CNT can enhance DET between enzymes and electrodes. The use of metal nanoparticles with CNT has been reported to form exceptionally stable and cost-effective biosensors.

\section{Glucose Biosensor}

Glucose concentration in blood is most frequently performed routine analyses in medicine. In recent years over $5 \%$ of the populations of industrialised nations have diabetes, resulting in a high demand for the detection of glucose in blood. Glucose concentration higher or lower than the normal range of $80-120 \mathrm{mg} \mathrm{dL}^{-1}$ (4.4-6.6 mM) leads to metabolic disorder of diabetes mellitus which results in the deficiency of insulin and hyperglycaemia. This disorder is a leading cause of death and disability. The diagnosis and management of the diseases requires close monitoring of blood glucose. The application of CNT in highly sensitive and cost-effective biosensors and can aid the diagnosis of the disorder diabetes mellitus.

\section{Enzymatic glucose biosensor}

Diabetes is a major health problem causing deaths worldwide. Thus, monitoring of glucose in blood has become a very important need leading to fabrication of accurate and sensitive advanced blood sugar detection devices for clinical diagnosis and personal care (Lee et al., 2016; Zaidi \& Shin 2016).

Direct electrochemistry of GOx involves DET between the electrode and the active centre of the GOx (Yu et al., 2014; Lee et al., 2016, Luong et al., 2017, Muguruma et al., 2017; Termehyousefi et al., 2017; Xia et al., 2017) (Fig.6). The direct electrochemistry of GOx based on redox-active centres was confirmed by $\mathrm{CV}$ experiments in the potential range of $0.8-1 \mathrm{~V}$ to follow previously proposed reaction mechanisms:

$\mathrm{GOx}(\mathrm{FAD})+2 \mathrm{H}++2 \mathrm{e}^{-} \leftrightarrow \mathrm{GOx}(\mathrm{FADH} 2)$ (In the absence of oxygen).......................(3)

In the presence of oxygen, the reaction mechanism follows different pathways:

$\mathrm{GOx}(\mathrm{FADH} 2)+\mathrm{O} 2 \rightarrow \mathrm{GOx}(\mathrm{FAD})+$

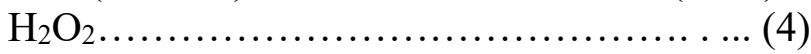

GOx(FAD) +Glucose $\rightarrow$ GOx(FADH2) + Gluconolactone ............................ (5)

Several researchers have used GOx for fabrication of carbon nanotube based glucose biosensor.

Buber et al. (2017) constructed a novel GOx based amperometric biosensor utilising a conducting polymer (CP), MWCNTs and a novel water soluble zinc phthalocyanine $(\mathrm{ZnPc})$. The constructed biosensor showed a linear response for glucose between $0.025-1.0 \mathrm{mM}$ with a detection limit of $0.018 \mathrm{mM}$. KM app and sensitivity values were calculated as $0.53 \mathrm{mM}$ and $82.18 \mu \mathrm{Amm}^{-1} \mathrm{~cm}^{-2}$, respectively. SEM) and CV techniques were used to investigate the surface modifications.

Liu et al. (2017) co-immobilised Glucoamylasedisplayed bacteria (GA-bacteria) and glucose dehydrogenase-displayed bacteria (GDH-bacteria) on MWNTs modified glassy carbon electrode (GCE) to construct GA-bacteria/GDHbacteria/MWNTs/GCE biosensor. The biosensor was developed by optimizing the loading amount and the ratio of GA-bacteria to GDH-bacteria. The as-prepared biosensor exhibited a wide dynamic 
range of $0.2-10 \mathrm{mM}$ and a low detection limit of $0.1 \mathrm{mM}$ maltose $(\mathrm{S} / \mathrm{N}=3)$. The biosensor also had a linear response to glucose in the range of $0.1-$ $2.0 \mathrm{mM}$ and a low detection limit of $0.04 \mathrm{mM}$ glucose $(\mathrm{S} / \mathrm{N}=3)$. Interestingly, at the same concentration, glucose was 3.75-fold sensitive than that of maltose at the proposed biosensor.

Gokoglan et al. (2017) fabricated a novel flexible glucose biosensor using vertically aligned carbon nanotubes (VACNT). The biosensor response at a potential of $-0.7 \mathrm{~V}$ versus $\mathrm{Ag}$ wire was followed by the decrease in oxygen level as a result of enzymatic reaction. The biosensor exhibited a linear range between $0.02 \mathrm{mM}$ and $0.5 \mathrm{mM}$ glucose and kinetic parameters $\left(K_{M}{ }^{a p p}\right.$, $I_{\max }$, limit of detection (LOD) and sensitivity) were estimated as $0.193 \mathrm{mM}, \quad 8.170 \mu \mathrm{A}$, $7.035 \times 10^{-3} \mathrm{mM}$ and $\quad 65.816 \mu \mathrm{A} / \mathrm{mM} \mathrm{cm}^{2}$, respectively. SEM was used for surface characterisation. The constructed biosensor was applied to determine the glucose content in several beverages.

Zhou et al. (2017) covalently linked Ferrocenegrafted dendrimer to the surface of CNTs (CNTs)chitosan (CS) nanocomposite modified electrode for immobilising high-content GOx, which resulted in the successful development a novel reagentless glucose biosensor. EIS, CV, and amperometry were used to characterise the preparation process and the enzymatically catalytic response of this biosensor. The biosensor showed excellent analytical performance such as fast response time less than 10 $\mathrm{s}$, wide linear range from 0.02 to $2.91 \mathrm{mM}$ and low detection limit down to $7.5 \mu \mathrm{M}$ as well as satisfactory stability and reproducibility toward the amperometric glucose determination. In addition, satisfactory result was obtained when it was used for the glucose measurements in human blood samples.

Uwimbabazi et al. (2017) recently, also developed glucose biosensor for the determination of the beef meat freshness based on a glassy carbon electrode (GCE) modified with MWCNTs and chitosan (Chi). They obtained a linear relationship between the current and the glucose concentrations in the range of 0.2 to 1.2 moll $\mathrm{L}-1$, at a signal-to-noise ratio of 3 a detection limit of $0.05 \mathrm{mM}$ was obtained with good linearity $(\mathrm{R} 2=0.9902)$, while the biosensor showed a rapid response to glucose. In addition, they applied the developed biosensor to determine the glucose in beef to indicate the freshness of the beef as compared to the total volatile basic nitrogen (TVB-N) method. They observed an increasing beef storage time.

With decreasing glucose level Amathatogachi et al. (2017) also reported a novel amperometric glucose biosensor based on GOx immobilised on a carbon nanotube (CNTs)-poly(diallyldimethylammonium chloride) (PDDA)-platinum nanoparticle (PtNPs) modified carbon-paste electrode (CNTs-PDDA-PtNPs/CPE). The CNTsPDDA-PtNPs composite materials were characterised by TEM and electrochemical techniques. $\mathrm{CV}$ results reveal direct electron transfer of the immobilised GOx, indicated by two quasi-reversible redox peaks at a potential of 0.37 $\mathrm{V}$ (vs. $\mathrm{Ag} / \mathrm{AgCl}$ ) in phosphate buffered solution (PBS) (0.10 M, pH 7). Glucose was quantified using amperometric measurements at $0.5 \mathrm{~V}$ vs. $\mathrm{Ag} / \mathrm{AgCl}$ and PBS carrier $(0.10 \mathrm{M}, \mathrm{pH} 7.0)$ at a flow rate of $1.0 \mathrm{~mL} \mathrm{~min}$. The linear working ranges for glucose measurements were $0.1-3 \mathrm{mM}\left(\mathrm{r}^{2}=0.995\right)$ and $5-100 \mathrm{mM}\left(\mathrm{r}^{2}=0.997\right)$, with corresponding sensitivities of 0.127 and $0.060(\mu \mathrm{A} \mathrm{s}) \mathrm{mM}^{-1}$, respectively.

Nenkova et al. (2017) prepared four enzyme electrodes (Pt/PAN/ GOx, Pt/PAN/NZ/ GOx, $\mathrm{Pt} / \mathrm{PAN} / \mathrm{NZ} / \mathrm{MNP} / \mathrm{GOx}, \mathrm{Pt} / \mathrm{PAN} / \mathrm{NZ} / \mathrm{MWNT} /$ GOx) by cross-linking of GOx on nanocomposite material. Amperometric measurement of the two glucose oxidase electrodes (Pt/PAN/NZ/ GOx and $\mathrm{Pt} / \mathrm{PAN} / \mathrm{NZ} / \mathrm{MWNT} / \mathrm{GOx}$ ) with best results was carried out. The linear concentration interval of the $\mathrm{Pt} / \mathrm{PAN} / \mathrm{NZ} / \mathrm{MWNT} / \mathrm{GOx}$ biosensor was up to 3 $\mathrm{mM}$, the detection limit $-0.02 \mathrm{mM}$ glucose and the storage stability $-81 \%$ of its initial current response after 30 days.

Kulkarni \& Slaughter (2017) described the characterisation of a self-powered glucose biosensor comprising of a MWCNTs modified with pyroquinoline quinone glucose dehydrogenase (PQQ-GDH) bioanode and bilirubin oxidase biocathode at physiological conditions. The assembly shows an enhancement in peak power and current densities as compared to the self-powered glucose biosensor comprising of PQQ-GDH 
bioanode and laccase biocathode. The assembly produced a maximum open circuit voltage of 480.1 $\mathrm{mV}$ and short circuit current density of $640 \mu \mathrm{A} / \mathrm{cm}^{2}$ with a peak power density of $89.27 \mu \mathrm{W} / \mathrm{cm}^{2}$. The self-powered glucose biosensor exhibited an extended linear dynamic range of $0.1 \mathrm{mM}$ to 35 $\mathrm{mM}$ with a sensitivity of $12.221 \mathrm{~Hz} / \mathrm{mM} \mathrm{cm}^{2}$. The use of bilirubin oxidase as the cathodic enzyme in addition to the design of biofuel cell assembly makes it a viable candidate as a potential power source for bioelectronics devices.

Lopes et al. (2017) used $\mathrm{TiO}_{2}$, glucose oxidase and carbon nanotube microparticles to provide a large surface area for enzyme immobilisation and a favourable microenvironment for direct electron transfer. This simple architecture nanostructure was used to construct a glucose oxidase biosensor, which demonstrated good analytical performance with high reproducibility, and good detection for pathological glucose level.

\section{Non Enzymatic Glucose Biosensor}

The number of people requiring glucose sensors has significantly increased over the last decade; there is an overwhelming demand for the development and improvement of glucose sensors. The demand to make sensors which are both biocompatible and have increased sensing capabilities as compared to current technologies is thus on the increase. In order to meet these needs, a move towards nonenzymatic glucose sensors has begun. Various researchers have begun fabrications of different nonenzymatic glucose biosensors:

He et al. (2017) reported that $\mathrm{La}_{0.6} \mathrm{Sr}_{0.4} \mathrm{CoO}_{3-\delta}$ (LSC) perovskite oxide can provide comparable performance to these noble metal nanomaterials. The best electrode, i.e., LSC $+\mathrm{RGO} / \mathrm{GCE}$ provides sensitivity of 500 and $330 \mu \mathrm{A} \mathrm{mM} \mathrm{mm}^{-1} \mathrm{~cm}^{-2}$ for $\mathrm{H}_{2} \mathrm{O}_{2}$ and glucose, respectively, and limit of detection of 0.05 and $0.063 \mu \mathrm{M}$ for $\mathrm{H}_{2} \mathrm{O}_{2}$ and glucose, respectively (at $\mathrm{S} / \mathrm{N}=3$ ). Its respective linear ranges are $0.2-3350 \mu \mathrm{M}$ and $2-3350 \mu \mathrm{M}$ for $\mathrm{H}_{2} \mathrm{O}_{2}$ and glucose, respectively.

Qiu et al. (2016) reported a one-step synthesis for the incorporation of nickel nanoparticles on CNTs is reported using thermal annealing with $\mathrm{NiCl}_{2}$ and melamine. The morphology and structure of the nickel nanoparticle modified CNTs were characterised by transmission electron microscopy, scanning electron microscopy, and powder X-ray diffraction. X-ray photoelectron spectroscopy demonstrated that the nickel nanoparticles were on the surface of CNTs forming a robust structure. The nickel nanoparticle modified CNTs rapidly oxidised glucose in alkaline solution with an excellent stability. Consequently, the modified CNTs were shown to be a suitable enzyme-free glucose electrochemical sensor when attached to a glassy carbon electrode, with excellent long term stability, a short response time, a low limit of detection, a long linear dynamic range, high sensitivity, and good precision.

Lee \& Kim (2016) demonstrated a simple and inexpensive method of carbohydrate detection using a field effect transistor (FET) with $\mathrm{Au}$ nanoparticles (AuNPs) attached to MWCNT, which does not require any enzymes or catalysts. The high sensitivity $\left(3.4 \mathrm{mM}^{-1}\right.$ for sucrose and $6.9 \mathrm{mM}^{-1}$ for glucose) of the sensor is adequate to diagnosis diabetes from a patient serum. The sensor is more sensitive to glucose than sucrose. The hypothesised detection mechanism of the FET sensor is a change of the potential barrier of the conductive MWCNT by the adsorption of the carbohydrates to the attached AuNPs

Baghayeri et al. (2016), developed a facile strategy to fabricate silver nanoparticles (Ag NPs) through an electrochemical method with the assistance of metformin functionalised MWCNT (Ag@MH/MWCNT nanocomposite). Investigations by field emission scanning electron microscopy (FESEM) confirmed that the prepared nanocomposite have a porous structure that is constructed by interconnecting functionalised MWCNT framework. Electrochemical studies showed that the nanocomposite exhibits high stability and excellent activity for electrocatalytic oxidation of glucose in alkaline solutions, which allows the Ag@MH/MWCNT to be used in enzyme-free amperometric sensors for glucose determination. It was confirmed that the Ag@MH/MWCNT based glucose biosensor presents wide response window for glucose concentrations of $1.0 \quad \mathrm{nM}-350 \mu \mathrm{M}$, short amperometric response time (4s), low detection 
limit of $0.0003 \mu \mathrm{M}(\mathrm{S} / \mathrm{N}=3)$, high sensitivity as well as good selectivity.

Li et al. (2016) prepared self-assembled $\mathrm{NiFe}_{2} \mathrm{O}_{4} /$ CNTs sponge by ice-templating method. The fabricated glucose biosensor exhibited two large linear ranges (0-3.0 and 3.2-12.4 mM) and distinct sensitivities (84.1 and $24.6 \mu \mathrm{A} \mathrm{mM}^{-1} \mathrm{~cm}^{-2}$ ).

Wang et al. (2015) fabricated porous $\mathrm{Pd}$ nanotubes on a GCE via a one-step galvanic replacement reaction by using cheap, flexible, and ultralong copper nanowires as the sacrificial template. The electrode exhibits excellent electrocatalytic performance for non-enzymatic glucose biosensors, thanks to massive pores and high specific surface area. This non-enzymatic glucose biosensor shows a wide linear response range from $5 \mu \mathrm{M}$ to $10 \mathrm{mM}$, with a sensitivity of $6.58 \mu \mathrm{A} \mathrm{mM}^{-1} \mathrm{~cm}^{-2}$, and a detection limit of $1 \mu \mathrm{M}$ (signal-to-noise ratio of 3 ).

\section{Hydrogen Peroxide Biosensor}

$\mathrm{H}_{2} \mathrm{O}_{2}$ is a simple molecule in nature but a most widely used oxidizing agent. The rapid and accurate analysis of $\mathrm{H}_{2} \mathrm{O}_{2}$ is of great importance in many fields including food industry, clinical control and environmental protection. Besides adoption in chemistry and food, $\mathrm{H}_{2} \mathrm{O}_{2}$ was also an important product present in several biological processes. $\mathrm{H}_{2} \mathrm{O}_{2}$ is a general enzymatic product of oxidases and a substrate of peroxidases, which is important in biological processes and biosensor development. $\mathrm{H}_{2} \mathrm{O}_{2}$ is also an essential mediator in food, pharmaceutical, clinical, industrial, and environmental analyses. $\mathrm{H}_{2} \mathrm{O}_{2}$ is present in higher concentrations around cancer cells as compared with normal analogues. It is because that $\mathrm{H}_{2} \mathrm{O}_{2}$ is not only a by-product of several highly selective oxidases, but also an essential mediator in food, pharmaceutical, clinical, industrial and environmental analyses.

\section{Enzymatic Hydrogen Peroxide Sensing}

Various research groups have used various enzymes for the fabrication of CNT based $\mathrm{H}_{2} \mathrm{O}_{2}$ sensors: Han et al. (2016) described a novel approach to construct an amperometric biosensor for determination of $\mathrm{H}_{2} \mathrm{O}_{2}$. HRP as a base enzyme was immobilised into the mixture of MWNTs and polyvinyl butyral (PVB). The results showed that the fabricated biosensor demonstrated significant electrocatalytic activity for the reduction of $\mathrm{H}_{2} \mathrm{O}_{2}$ with wide linear range from 0.000832 to 0.6 $\mathrm{mM}$, and low detection limit $0.000167 \mathrm{mM}(\mathrm{S} / \mathrm{N}=$ 3) with fast response time less than $8 \mathrm{~s}$. The apparent Michaelis-Menten constant was determined to be $0.049 \mathrm{mM}$. Additionally, the biosensor exhibited high sensitivity, rapid response and good long-term stability.

Deb et al. (2016) fabricated a composite capable of detecting multiple anolytes is important for advancing rapid medical diagnosis technology to assist in treating illnesses. A dendrimerencapsulated $\mathrm{Pt}$ nanoparticle carbon nanotube $(\mathrm{Pt}-$ DEN-PANI-CNT) composite-based electrochemical biosensor was fabricated for the detection of $\mathrm{H}_{2} \mathrm{O}_{2}$, ascorbic acid (AA), and acetaminophen (AP), important for monitoring AP overdose-induced poisoning. Polyaniline (PANI) was used to coat single-walled CNTs, which were then decorated with Pt-encapsulated, fourthgeneration NH2-terminated poly(amidoamine) (G4-PAMAM) dendrimers. XPS and attenuated total reflectance infrared (ATR-IR) spectroscopies, and TEM were used to characterise the nanocomposite material. Electrocatalytic activity of the Pt-DEN-PANI-CNT composite was studied using $\mathrm{CV}$ and chronoamperometric (CA) techniques. Point-of-zero charge (PZC) measurements showed that the isoelectric point of the composite was at $\mathrm{pH} 6.8$, an important parameter to consider in explaining differences in selectivity of the composite to these various analytes. Measured chronoamperometric signals for AA, $\mathrm{H}_{2} \mathrm{O}_{2}$, and AP were found in the concentration ranges of $10 \mu \mathrm{M}-10 \mathrm{mM}, 50 \mu \mathrm{M}-$ $8 \mathrm{mM}$, and $20 \mu \mathrm{M} \mathrm{mM}$, respectively. Within this series of analytes, the Pt-DEN-PANI-CNT composite can selectively detect both $\mathrm{H}_{2} \mathrm{O}_{2}$ and AP, separately, in the presence of the other analytes with rapid current response (5 s) and good reproducibility.

Anajocic et al. (2016) also compared traditional paraffin oil and graphite powder based carbon paste electrode (CPE) surface modified with MWCNTs with composites of $\mathrm{MnO}_{2}-\mathrm{MWCNT}$ or PtMWCNT by drop coating method to prepare simply, sensitive and reliable voltammetric sensors either for the determination of $\mathrm{H}_{2} \mathrm{O}_{2}$ or after 
additional modification of the appropriate sensor surfaces with GOx for the determination of glucose via $\mathrm{H}_{2} \mathrm{O}_{2}$ in selected samples. The SEM characterisation in combination with energy dispersive X-ray spectrometry of the composite materials confirmed that the mediators, $\mathrm{MnO}_{2}$ and $\mathrm{Pt}$ particles, are randomly distributed on the surface of the MWCNTs, and represent nearly 5\% (m: m) of the composites expressed as $\mathrm{Pt}$ and $\mathrm{Mn}$. CV investigations were performed in acetate $(\mathrm{pH} 4.50)$, phosphate $(\mathrm{pH} 7.50)$ and borate $(\mathrm{pH} 9.18)$ buffers to characterise the basic electrochemical behaviors and to select the working potentials suitable for hydrodynamic chronoamperometric (HA) determination of $\mathrm{H}_{2} \mathrm{O}_{2}$ under different circumstances.

Vilian et al. (2015) also designed a novel composite film for use as a highly selective mediator-free amperometric biosensor, and a method was created for accomplishing direct electrochemistry of myoglobin on a MWCNT and tyramine-modified composite decorated with $\mathrm{Au}$ nanoparticles on a glassy carbon electrode. The ultraviolet-visible and electrochemical impedance spectroscopy results showed that myoglobin retained its native conformation in the interaction with Au-PTy-f-MWCNT. The surface coverage of Mb-heme-Fe (II)/(III) immobilised on Au-PTy-fMWCNT and the heterogeneous electron-transfer rate constant were $2.12 \times 10$ â ' 9 mol cm â ' 2 and $4.86 \mathrm{~s}$ â '1, respectively, indicating a higher loading capacity of the nanocomposite for direct electron transfer of $\mathrm{Mb}$ onto the electrode surface. The proposed Mb/Au-PTy-f-MWCNT biofilm exhibited excellent electrocatalytic behavior toward the reduction of $\mathrm{H}_{2} \mathrm{O}_{2}$ and the oxidation of nitrite with linear ranges of 2 to 5000 I $1 / 4 \mathrm{M}$ and 1 to 8000 I $1 / 4 \mathrm{M}$ and lower detection limits of $0.01 \hat{\mathrm{I}}$ 1/4M and 0.002 I 1/4M, respectively. An apparent Michaelis-Menten constant of $0.12 \mathrm{mM}$ indicated that the Mb immobilised on the Au-PTy-f-MWCNT film retained its native activity. This biosensor can be successfully applied to detect $\mathrm{H}_{2} \mathrm{O}_{2}$ and nitrite in disinfectant cream, eye drops, pickle juice, and milk samples.

Zhang et al. (2015) achieved a large-scale synthesis of a three-dimensional (3D) nitrogendoped carbon nanotube (NCNT) film via electrospinning assisted by a chemical vapour deposition procedure. The resulting nanostructure with dense and uniform NCNTs was tightly bonded onto the electrospun carbon nanofiber matrix. The novel biomimetic $\mathrm{H}_{2} \mathrm{O}_{2}$ biosensor has a low detection limit $(0.03 \mathrm{mM} \mathrm{S} / \mathrm{N}=3)$ and a wide linear range (0.08-137.2 $\mathrm{mM})$. In addition, the biosensor exhibited high reproducibility, good storage stability, and satisfactory anti-interference ability. The facile preparation method and attractive analytical performances make this robust electrode material promising for the development of effective electrochemical sensors.

Thandavan et al. (2015) developed a hybrid interface using nano iron oxide and CNTs and this architecture offered an improved performance for the detection of $\mathrm{H}_{2} \mathrm{O}_{2}$. The morphology of the prepared nanocomposite was observed using FETEM and the electrochemical studies were carried out using cyclic voltammetry and amperometry. The linear range of the prepared amperometric sensor was found to be between 1.2 and $21.6 \mu \mathrm{M}$ with a quick response time of less than $1 \mathrm{~s}$. The interference, reproducibility and stability studies were carried out with satisfactory results. The limit of detection and limit of quantification were found to be $3.7 \mathrm{nM}$ and $12.2 \mathrm{nM}$ respectively. With the convincing results obtained in terms of the performance of the biosensor, this platform was successfully upgraded for the determination of $\mathrm{H}_{2} \mathrm{O}_{2}$ as in the presence of milk samples.

\section{Non-Enzymatic Hydrogen Peroxide Sensing}

Enzymeless detection of $\mathrm{H}_{2} \mathrm{O}_{2}$ and glucose offers a more reliable and accurate detection route given the absence of enzyme that is sensitive to temperature, $\mathrm{pH}$, poisoning chemicals, and humidity.

Various research groups have used CNT for fabrication of non -enzymatic $\mathrm{H}_{2} \mathrm{O}_{2}$ biosensor:

Lorencova et al. (2017) reported the use of Ti3C2Tx for ultrasensitive detection of $\mathrm{H}_{2} \mathrm{O}_{2}$ down to NM level with a response time of $\sim 10 \mathrm{~s}$, while

Wang et al. (2016) successfully anchored $\mathrm{Ni}(\mathrm{II})$-Based metal-organic framework (Ni(II)MOFs) on CNTs by in situ solvothermal method. In the as-prepared composites, 2 3 nm MOFs nanoparticles homogeneously dispersed on 
conducting. As the electrode materials of a nonenzymatic $\mathrm{H}_{2} \mathrm{O}_{2}$ biosensor, the $\mathrm{Ni}(\mathrm{II})-\mathrm{MOF} / \mathrm{CNTs}$ exhibited excellent electrocatalytic performance including a wide linear detection range from 0.01 to $51.6 \mathrm{mmol} \mathrm{L}^{-1}$, low detection limit of $2.1 \mu \mathrm{mol}$ $\mathrm{L}^{-1}$ and very fast response of $2.5 \mathrm{~s}$ for $\mathrm{H}_{2} \mathrm{O}_{2}$ sensing..

Bai et al. (2016) prepared a novel enzyme-free $\mathrm{H}_{2} \mathrm{O}_{2}$ sensor composed of carbon dots (CDs) and MWCNTs. It was found that the carbon dotsdecorated multi-walled carbon nanotubes nanocomposites (CDs/MWCNTs) modified glassy carbon (GC) electrode (CDs/MWCNTs/GCE) exhibited a significant synergistic electrocatalytic activity towards $\mathrm{H}_{2} \mathrm{O}_{2}$ reduction as compared to carbon dots MWCNTs alone, and the $\mathrm{CDs} / \mathrm{MWCNTs} / \mathrm{GCE}$ has shown a low detection limit as well as excellent stability, selectivity, and reproducibility.

Baghayeri et al. (2015) constructed a sensitive amperometric biosensor for $\mathrm{H}_{2} \mathrm{O}_{2}$ based on synergetic catalysis of haemoglobin and porous $\mathrm{PdFe}_{3} \mathrm{O}_{4}-\mathrm{MWCNT}$ nanocomposite. With attention to the utilities of large surface area and outstanding catalytic performance, $\mathrm{PdFe}_{3} \mathrm{O}_{4}-\mathrm{MWCNT}$ nanocomposite was employed as the nanostabiliser for the immobilisation of $\mathrm{Hb}$. The immobilised $\mathrm{Hb}$ on the surface of nanocomposite as an electrochemical biosensor efficiently catalysed the reduction of $\mathrm{H}_{2} \mathrm{O}_{2}$, amplified the electrochemical signal and enhanced the sensitivity. A linear response from $0.2-500 \mu \mathrm{M}$ with detection limit of $0.063 \mu \mathrm{M}$ for $\mathrm{H}_{2} \mathrm{O}_{2}$ was achieved. The apparent Michaelis-Menten constant KappM value was $21 \mu \mathrm{M}$.

\section{Cholesterol Biosensing}

Cholesterol and its ester are essential constituents of all animal cells. They are precursors of bioanalytes such as bile acid and steroid hormones. Increase in cholesterol levels can cause life-threatening coronary heart diseases, cerebral thromboses, and artherosclerosis. Consecuently accurate detection of cholesterol level is medically useful. Cholesterol that is responsible for cardiovascular disease can be effectively managed by a combination of medication and monitoring and there continues to be a need for new point-of-care diagnostics to measure lipid panels, including total cholesterol (Ahmadraji \& Killard 2016). .Enzyme assays based on the generation of $\mathrm{H}_{2} \mathrm{O}_{2}$ have been very effective in this regard. $\mathrm{ChOx}$ is an enzyme promoting the oxidation of cholesterol, generating $\mathrm{H}_{2} \mathrm{O}_{2}$ in the presence of oxygen. Cholesterol enzyme sensors use $\mathrm{ChOx}$ to produce hydrogen peroxide for electrochemical detection, with carbon nanotube lowering the over-potential. Several researchers have fabricated CNT based cholesterol biosensor:

Luo et al. (2017) synthesised nonstoichiometric $\mathrm{CeO}_{2} \mathrm{CNT}$ core/shell nanowire arrays (NWAs) by hydrothermal method in combination with chemical vapour deposition. Morphology and microstructure of the core/shell NWAs were characterised by SEM, XRD, TEM and Raman spectrum techniques. They showed high sensitivity of $336.6 \mu \mathrm{A} \mathrm{cm}^{-2} \mathrm{mM}^{-1}$ and low detection limit of $7.4 \mu \mathrm{m}$ towards cholesterol detection at working potential of $-0.4 \mathrm{~V}$ due to synergistic effect of nonstoich iometric $\mathrm{CeO}_{2}$ and $\mathrm{CNT}$, and they also demonstrated excellent selectivity towards interferents co-existing with cholesterol in blood serum.

$\mathrm{Xu}$ et al. (2016) constructed a simple and high sensitive cholesterol amperometric biosensor, which is based on in situ electropolymerisation of multi-walled carbon nanotube-polyaniline (MWCNT-PANI) nanocomposite and electrodeposition of platinum nanoparticle (nano$\mathrm{Pt}$ ) films onto the glassy carbon electrode surface for cholesterol oxidase immobilisation. The preparation process of the modified electrode was characterised by $\mathrm{CV}$, EIS, SEM, and chronoamperometry. Because of the synergistic electrocatalytic activity between MWCNT-PANI nanocomposites and nano-Pt, the cholesterol biosensor exhibited an excellent performance with a linear range of 2.0-510.0 $\mu \mathrm{M}$, a detection limit of $0.8 \mu \mathrm{M}$ ( signal-to-noise ratio $=3$ ), a high sensitivity of $109.9 \mu \mathrm{A} \mathrm{mM}^{-1}$, and a short response time within 5 Sec.

Pandy et al. (2016) who designed a novel and improved membranous support for electrochemical sensing of cholesterol by the application of CNT. ChOx was immobilised on the CNTs mixed cellulose acetate membrane (CA-CNT). SEM 
images have shown that $\mathrm{ChOx}$ is uniformly immobilised over the CA-CNT membrane. The electrocatalytic responses of $\mathrm{ChOx} / \mathrm{CA}-\mathrm{CNT}$ were investigated with various concentration of cholesterol ranging from $10^{-3} \mathrm{M}$ to $10^{-8} \mathrm{M}$. Compared with $\mathrm{ChOx} / \mathrm{CA}$, the $\mathrm{ChOx} / \mathrm{CA}-\mathrm{CNT}$ has better electrocatalytic response to cholesterol. This sensor shows excellent performance with high sensitivity, with a linear range of $10^{-3} \mathrm{M}$ to $10^{-8} \mathrm{M}$, and a detection limit of $10^{-8} \mathrm{M}$.

Qian et al. (2015) synthesised multiwalled carbon nanotube@reduced graphene oxide nanoribbon (MWCNT@rGONR) core-shell heterostructures by the facile unzipping of MWCNTs and subsequent chemical reduction with hydrazine. MWCNTs with diameter $<10 \mathrm{~nm}$ were selected as the starting material to maintain narrow ribbons $<30 \mathrm{~nm}$ wide with a few-layer structure..

\section{Nicotinamide Adenine Dinucleotide (NADH) Biosensor}

$\mathrm{NADH}$ is an important coenzyme that takes part in more than 300 dehydrogenase enzymatic reactions. $\mathrm{NADH}$ is involved as a cofactor in over 300 enzymatic reactions of $\mathrm{NAD}+\mathrm{NADH}$ dependent dehydrogenases. The application of amperometric NADH sensors provide a promising measurement technique for detection of substrate or enzymatic activity. But, the direct oxidation of $\mathrm{NADH}$ at ordinary electrodes often requires high overpotential and suffers from low sensitivity and the fouling of the electrode surface by its oxidation products. CNTs are recently attracting growing attention in decreasing the high overpotential for $\mathrm{NADH}$ oxidation and minimising the surface fouling. The NADH generated can be detected by electrochemical oxidation at appropriate electrodes. Electrocatalytic oxidation of NADH has been investigated as part of the development of dehydrogenase-based biodevices. However, its electrochemical oxidation at bare GC electrodes in neutral solutions occurs at a high overpotential ( 0.5 $\mathrm{V})$ because of slow ET kinetics and electrode fouling. Therefore, the effective oxidation of $\mathrm{NADH}$ at low potentials would aid the development of NADH-based bio devices. Various researchers have fabricated $\mathrm{CNT}$ based NADH biosensor:
Atta et al. (2017) used Glassy carbon (GC) electrode modified by stepwise manual casting of successive layers of ionic liquid crystals (ILC)/CNTs and magnetite nanoparticles. The composite $\left.\left[\mathrm{GC} / \quad(\mathrm{ILC}-\mathrm{CNTs}) / \mathrm{Fe}_{3} \mathrm{O}_{4}\right)\right]$ as a successful NADH biosensor. The proposed NADH sensor has th following properties: linear dynamic range of $5-700 \mu \mathrm{mol} \mathrm{L}^{-1}$, a sensitivity of $0.0102 \mu \mathrm{A} \mu \mathrm{mol}^{-1} \mathrm{~L}$, a detection limit of $34.6 \mathrm{nmol} \mathrm{L}^{-1}$ and a limit of quantification of $0.115 \mu \mathrm{mol} \mathrm{L}^{-1}$. The sensor showed a stable amperometric response and anti-interfering ability in presence of ascorbic acid, tryptophan, ibuprofen and morphine.

Hamidi \& Haghig (2016) synthesised palladium nanoparticles decorated multiwalled carbon nanotubes (PdNPs-MWCNTs) and simply cast on the surface of a GCE to prepare an amperometric sensor. The fabricated sensor (PdNPsMWCNTs/GCE) showed excellent electrocatalytic activity towards NADH and $\mathrm{H}_{2} \mathrm{O}_{2}$ oxidation and $\mathrm{H}_{2} \mathrm{O}_{2}$ reduction. It has a fast, linear and highly sensitive response for NADH in the concentration range between 0.1 and $200 \mu \mathrm{M}$ with a detection limit $(\mathrm{S} / \mathrm{N}=3)$ of $32 \mathrm{nM}$ and exhibited fast and sensitive responses $\left(<2\right.$ s) towards $\mathrm{H}_{2} \mathrm{O}_{2}$. The sensitivity and detection limit for $\mathrm{H}_{2} \mathrm{O}_{2}$ at the operating potential of $+0.35 \mathrm{~V}$ were $167 \mathrm{nA} \mu \mathrm{M}^{-1}$ $\mathrm{cm}^{-2}$ and $1.2 \mu \mathrm{M}$, respectively and better than those obtained at the operating potential of $-0.25 \mathrm{~V}(68$ $\mathrm{nA} \mu \mathrm{M}^{-1} \mathrm{~cm}^{-2}$ and $\left.14 \mu \mathrm{M}\right)$. Moreover, further modification of the proposed sensor by glucose oxidase led to the fabrication of a glucose biosensor with satisfactory performance.

Eguilaz et al. (2016) reported the use of SWCNT covalently functionalised with polytyrosine (Polytyr) (SWCNT-Polytyr) as a new electrode material for the development of NADH-based biosensors. The oxidation of GCE modified with SWCNT-Polytyr at potentials high enough to oxidise the tyrosine residues have allowed the electrooxidation of NADH at low potentials due to the catalytic activity of the quinones generated from the primary oxidation of tyrosine without any additional redox mediator. The amperometric detection of NADH at $0.200 \mathrm{~V}$ showed a sensitivity of $(217 \pm 3) \mu \mathrm{A} \mathrm{mM}^{-1} \mathrm{~cm}^{-2}$ and detection limit of $7.9 \mathrm{nM}$. 


\section{Immunosensor}

In developed and developing countries where cancer and cardiovascular diseases are rampant, there is a growing demand for a range of portable, rapid and low cost biosensing devices for the detection of these diseases. Analytical immunosensor have been used to diagonise early detections of these diseases. Immunosensors are based on the high affinity reactions antigen/antibody. As a result of the specific binding of antibody to its corresponding antigen, immunosensors based on antibody-antigen interaction are one of the most widely used analytical techniques in the quantitative detection of biomolecules, metal ions, and diseases in blood. Electrochemical immunosensors have sensitive detection limits to monitor both levels of the biomarkers in normal and patient serum. They are simple, rapid, reliable and inexpensive devices.

Electrochemical immunosensors based on antibody specific recognition of its antigen and subsequently transfer the recognition to amperometric, potentiometric, impedimetric conductometric signals to quantify antigen concentrations. Advanced carbon materials were frequently employed in immunosensors due to their adsorption characteristics and excellent electrocatalytical performance. Several strategies can be used to immobilise the recognition element, either the antibody or the antigen, depending on the selected scheme. The detection of the recognition event uses the same principle as the enzymatic immunoassay. In general, an enzyme is coupled to the recognition layer (the antigen or antibody) and the enzymatic reaction is developed once the antigen/antibody interaction occurred and after the addition of the substrate and electrochemically detection of the product. Immunosensor has the benefits of portability, fast response, simple operation, and low cost and has the potential for the development of rapid disease screening devices. Various research groups have fabricated CNT based immunosensor.

Han et al. (2017) constructed a novel sensitive, synthetic silver nanoparticles-carbon nanotube/manganese dioxide (Ag NPsMWCNTs $/ \mathrm{MnO}_{2}$ ) which was used as labels of secondary antibodies $\left(\mathrm{Ab}_{2}\right)$ which improved the surface of electrode and enhanced the electrochemical signal. $\mathrm{MnO}_{2}$ and $\mathrm{Ag}$ NPs achieve dual signal amplification to improve the sensitivity effectively. Under the optimal conditions, the electrochemical immunosensor exhibited a wide linear range of $0.0001-0.5 \mathrm{ng} \cdot \mathrm{mL}^{-1}$ and $0.5-$ $10 \mathrm{ng} \cdot \mathrm{mL}^{-1}$ respectively with a low detection limit of $0.03 \mathrm{pg} \cdot \mathrm{mL}^{-1}$ for CEA.

Sánchez-Tirado et al. (2017) used dual screenprinted carbon electrodes modified with 4carboxyphenyl-functionalised double-walled carbon nanotubes (HOOC-Phe-DWCNTs/SPCEs) as scaffolds for the preparation of electrochemical immunosensors for the simultaneous determination of the cytokines Interleukin-1 $\beta$ (IL-1 $\beta$ ) and factor necrosis tumor $\alpha$ (TNF- $\alpha)$. The achieved limits of detection were $0.38 \mathrm{pg} / \mathrm{mL}$ (IL-1 $\beta$ ) and $0.85 \mathrm{pg} / \mathrm{mL}$ $(\mathrm{TNF}-\alpha)$.

Sharma et al. (2017) immobilised Antigen over the surface of gold nanoparticle/multi-walled carbon nanotube (Nano-Au/C-MWCNT) screen printed electrodes using 1-Ethyl-3-(3dimethylaminopropyl) carbodiimide (EDC)/Nhydroxysuccinimide (NHS) cross linking chemistry followed by interaction with groundnut bud necrosis virus (GBNV)/CaCV specific polyclonal antibody. The electrochemical response was measured by $\mathrm{CV}$, differential pulse voltammetry (DPV) using the redox indicator. Electrode surface characterisation was done by performing SEM. Electrochemical studies showed positive results at different antigenic dilutions ranging from $10^{-2}-8 \times 10^{-5}$.

Guner et al. (2017) developed an electrochemical immunosensor for the common food pathogen Escherichia coli O157:H7. This novel immunosensor based on the PPy/AuNP/MWCNT/Chi hybrid bionanocomposite modified pencil graphite electrode (PGE). The prepared bionanocomposite platform and immunosensor was characterised by using CV. Concentrations of E. coli O157:H7 from $3 \times 10^{1}$ to $3 \times 10^{7} \mathrm{cfu} / \mathrm{mL}$ could be detected. The detection limit was $\sim 30 \mathrm{cfu} / \mathrm{mL}$ in PBS buffer. Furthermore, Liu et al. (2017) described a labelfree amperometric immunosensor for the direct determination of ZENs. A glassy carbon electrode (GCE) was first modified with polyethyleneimine- 
functionalised MWCNTs. Next, gold and platinum nanoparticles (AuPt-NPs) were electro-deposited. This process strongly increased the surface area for capturing a large amount of antibodies and enhanced the electrochemical performance. In a final step, monoclonal antibody against zearalenone was orientedly immobilised on the electrode, this followed by surface blocking with BSA. The resulting biosensor was applied to the voltammetry determination of ZENs, best at a working voltage of $0.18 \mathrm{~V}$ (vs SCE). Under optimised conditions, the method displays a wide linear range that extends from 0.005 to $50 \mathrm{ng} \mathrm{mL}^{-1}$, with a limit of detection of $1.5 \mathrm{pg} \mathrm{mL}^{-1}$ (at an $\mathrm{S} / \mathrm{N}$ ratio of 3).

Hien et al. (2017) also successfully developed an effective electrochemical method to produce polyaniline/multiwalled CNTs nanocomposite on interdigitated platinum microelectrodes for the enhancement of biosensing performance. Morphology and structure of nanocomposite were investigated by field emission scanning electron microscopy and UV-visible spectroscopy. FTIR technique was used to identify the presence of polyaniline/MWCNTs on the surface of microelectrodes. IgG polyclonal antibodies against Japanese encephalitis virus (JEV) were immobilised onto nanocomposite-modified microelectrodes, acting as an electrochemical immunosensor for label-free detection of JEV antigens. Results showed that the linear detection range of the immunosensor for JEV antigens was $2-250 \mathrm{ng} / \mathrm{mL}$. The EIS analysis also indicated that a negligible response was found when the immunosensor exposed to non-specific molecules. This work showed the potential use of polyaniline/MWCNTs nanocomposite in the platform of electrochemical immunosensors for label-free detection of pathogens and small biomolecules.

Li et al. (2017) designed and fabricated a sensitive sandwich-type non-enzymatic electrochemical immunosensor for quantitative detection of squamous cell carcinoma antigen (SCCA). They used silver nanoflowermolybdenum disulfide/multiwalled carbon nanotubes (SNFs-NH2-MoS2/MWCNTs) as labels of secondary antibodies (Ab2) and exhibit remarkable multiple-signal amplification effects. The immunosensor shows a wide linear range between $0.1 \mathrm{pg} \mathrm{mL}^{-1}$ and $20 \mathrm{ng} \mathrm{mL}^{-1}$ with a limit of detection $0.03 \mathrm{pg} \mathrm{mL}^{-1}$.

\section{DNA Sensors}

DNA a carrier of genetic information is considered to play a significant role in genetics and medical diagnosis. It is one of the most important intracellular targets that undergo modification and damage upon interaction with endogenous and exogenous factors. It is an excellent biomaterial for the construction of new devices, in nanotechnology and biosensor technology, for evaluation of DNA interaction with a broad range of chemical compounds and biomolecules, essential from a biological and a medical point of view. The electrochemical detection of DNA has also attracted extensive attention because of high sensitivity, high selectivity and low cost for the detection of selected DNA sequences or mutated genes associated with human diseases.

In DNA biosensors the biorecognition layer is a DNA molecule. There are, basically, two types of DNA biosensors, for the detection of the hybridisation event and for the detection of the DNA-drugs interaction or DNA damage. There are two fundamental aspects in the development of hybridisation biosensors, sensitivity and selectivity. Traditional methods for detecting the hybridisation event are too slow and require special preparation. Therefore, there is a great interest for developing new hybridisation biosensors, and the electrochemical ones represent a very interesting alternative.

An electrochemical DNA hybridisation biosensor basically consists of an electrode modified with a single stranded DNA. The first and most critical step is the immobilisation of DNA probe on the electrode in the preparation of DNA biosensor (Fig. 7). Hybrid formation under selected conditions of $\mathrm{pH}$, temperature and ionic strength is the second step while the last one, involves the detection of the double helix formation by a given methodology that allows obtaining an electrical signal that clearly demonstrates that the sequence-specific biorecognition event has taken place. Biosensors containing DNA as 
biorecognition layer also allow the detection of chemical and physical damage in DNA. In this case, it is necessary to immobilise preferentially double stranded DNA at the electrode surface to build the biosensor. The next step consists of the interaction of the DNA layer confined to the electrode with the given damage agent under controlled conditions, while the last step is the transduction of the signal, either from the oxidation/reduction of the nucleobases, damage agent, and/or the corresponding adducts. Various research groups have fabricated CNT based DNA biosensor: (a)

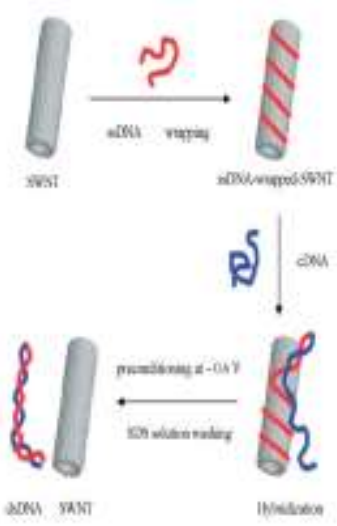

(b)

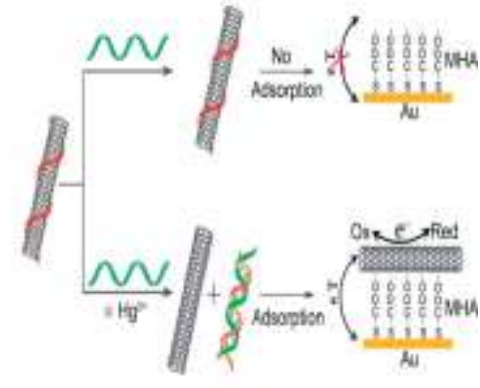

was determined and evaluated by changes in the intrinsic guanine oxidation signal at about $1.0 \mathrm{~V}$ by DPV. Numerous factors affecting the hybridisation were optimized such as target concentration, hybridisation time, etc. The designed DNA sensor can well detect E. coli DNA in 20 min detection time with 0.5 pmole of detection limit in $30 \mu \mathrm{L}$ of sample volume.

Sadrabadi et al. (2016) designed a biosensor as a new, rapid, and sensitive tool for investigation of binding of zearalenone with double-stranded DNA (dsDNA). Polydiallyldimethylammonium chloride (PDDA) as a polycation and MWCNTs provide a positively charged surface with a high surface area for the immobilisation of dsDNA as a polyanion on the surface of pencil graphite electrode (PGE). Using the dsDNA/MWCNT-PDDA-modified PGE, it was possible to detect the interaction of zearalenone with dsDNA, which allowed application of the dsDNA-modified electrode for trace determination of zearalenone. By using dsDNA/PDDA-MWCNT/PGE, zearalenone could be detected as low as $0.005 \mathrm{ng} \mathrm{mL}^{-1}$. The relative standard deviation of five measurements of $0.5 \mathrm{ng} \mathrm{mL}-1$ zearalenone was found to be $4.2 \%$.

Mainwhile et al. (2016) presented a microfluidic-multiplexed platform that integrates electrochemical sensors based on CNTs associated with ferrocene as redox marker (carbon nanotube $(\mathrm{CNT}) /$ ferrocene) for direct detection of pathogenic viral DNA from Hepatitis C and genomic. DNA from Mycobacterium tuberculosis in clinical isolates. By operating the fluidic device under high flow $(150 \mu \mathrm{l} / \mathrm{min})$, the formation of a very thin depletion layer at the sensor surface $(\delta S=230 \mathrm{~nm})$ enhances the capture rate up to one DNA strand per second. This microfluidic device working under high flow allows selective direct detection of a Mycobacterium tuberculosis (H37Rv) rpoB allele from clinical isolate extracted DNA.

Zhang (2016) developed a novel sensing platform based on $\mathrm{Fe}_{3} \mathrm{O}_{4}$ nanoparticles functionalised CNTs for highly sensitive label-free detection of $\mathrm{BCR} / \mathrm{ABL}$ fusion gene from chronic myelogenous leukemia. Under optimal conditions, the dynamic range for detecting the sequencespecific DNA of the $\mathrm{BCR} / \mathrm{ABL}$ fusion gene was 
from $1.0 \times 10^{-15}$ to $1.0 \times 10^{-9} \mathrm{~mol} \mathrm{~L}^{-1}$ and the detection limit was $2.1 \times 10^{-16} \mathrm{~mol} \mathrm{~L}^{-1}$.

Taei et al. (2016) also prepared $\mathrm{Fe}_{2} \mathrm{O}_{3} / \mathrm{SnO}_{2}$ nanocomposite by a solid-phase method in an alkaline medium. The $\mathrm{Fe}_{2} \mathrm{O}_{3} / \mathrm{SnO}_{2}$ composite was characterised by X-ray diffraction, field emission scanning electron microscopy, and Fourier transform infrared spectroscopy. A sensitive electrochemical biosensor is also presented for the determination of doxorubicin (DOX) based on a dsDNA-decorated multiwalled carbon nanotubes$\mathrm{Fe} 2 \mathrm{O} 3 / \mathrm{SnO} 2$-chitosan (ds-DNA-MWNTs$\mathrm{Fe}_{2} \mathrm{O}_{3} / \mathrm{SnO}_{2}$ CHIT) modified pencil electrode. DOX has shown an oxidation peak at $0.34 \mathrm{~V}$ on the surface of the bare pencil graphite electrode (PGE) in $\mathrm{pH}$ 7.0. The presence of DNA results in a decrease in the current; moreover, a positive shift in the DOX oxidation peak indicates an intercalative interaction. Finally, a PGE modified with ds-DNAMWNTs-Fe2O3/SnO2 CHIT was tested in order to determine the DOX content in the solution. The dynamic range was from 20.0 to $5552.0 \mathrm{nmol} \mathrm{L}^{-1}$ with a detection limit of $0.004 \mathrm{nmol} \mathrm{L}^{-1}$. This sensing platform showed other advantages such as simplicity, good stability, and high sensitivity.

Abdel-Hamid \& Newair (2016) used MWCNTsmodified glassy carbon electrode biosensor for electrochemical studies of caffeic acid-dsDNA interaction in phosphate buffer solution at $\mathrm{pH} 2.12$. Caffeic acid, CAF, shows a well-defined cyclic voltammetric wave. The oxidative damage caused to DNA was detected using the biosensor. The damage caused by the reactive oxygen species, hydroxyl radical $(\mathrm{OH})$ generated by the Fenton system on the DNA-biosensor was detected. It was found that CAF has the capability of scavenging the hydroxide radical and protecting the DNA immobilised on the GCE surface.

Wang et al. (2016) fabricated an electrochemical biosensor based on MWCNTs and $\mathrm{Hb}$ in order to explore the DNA damage mechanism induced by endogenous factors and the activities of the antioxidants. When the glassy carbon electrode (GCE) modified with chitosan (CS), double stranded DNA (ds-DNA), MWCNTs and $\mathrm{Hb}$ was subjected to a negative potential of $-1.4 \mathrm{~V}$ in PBS of $\mathrm{pH} 5.8$, the dissolved oxygen was reduced to $\mathrm{H}_{2} \mathrm{O}_{2}$ on the surface of the MWCNTs. Then the
$\mathrm{H}_{2} \mathrm{O}_{2}$ reacted with $\mathrm{Hb}$ and formed a Compound $\mathrm{I}$ (Hb-C-HOOH) and $\mathrm{H} 2 \mathrm{O}$. The Compound I, highly oxidising specie, can be used as reactive oxygen species (ROS) and to damage DNA in situ in the membrane. The ascorbic acid (AA) can protect the DNA from damage by scavenging the $\mathrm{H}_{2} \mathrm{O}_{2}$ to inhibit the formation of the Compound I. The dsDNA oxidative damage degree and the protective effect of AA from DNA damage were monitored by $\mathrm{CV}$, EIS and ultraviolet-visible spectroscopy (UVvis).

\section{Ascorbic Acid (AA), Uric Acid (UA), Dopamine (DA)}

Dopamine (3,4-dihydroxylphenyl ethylamine) (DA) is the most significant neurotransmitter in the human nervous system. Abnormal dopamine levels cause fatal neurological disorders, and thus measuring dopamine level in actual samples is important. DA is one of catecholamine neurotransmitters which have impact on cognitive and behavioural functions in animals, including humans. Lack of DA is one of the reasons of Parkinson's disease. A deficiency of dopamine in the brain is believed to cause schizophrenia and Parkinson's disease. This makes the sensing of dopamine in brain tissue so vital in clinical diagnoses. DA also plays a significant role in the central nervous, renal, hormonal, and cardiovascular systems. Ascorbic acid, Vitamin C, is an anion at physiological $\mathrm{pH}$ that can undergo a two-electron transfer oxidation while Uric acid is the final product of purine metabolism and related to disorders such as hyperuricemia and Lesche Nyhan syndrome (Pisoschi et al. 2014).

UA and AA are significant health biomarkers and will cause overlapping voltametric response and result in unexpected interferences under simultaneous detections with DA. Although electrochemical methods have been developed for detecting dopamine with high accuracy, certain substances (e.g., ascorbic acid) in actual samples often interfere with electrochemical dopamine detection. Because dopamine, ascorbic acid, and uric acid have similar oxidation potentials and often coexist in biological samples, many researchers have simultaneously determined DA, AA and UA using various methods: 
Ghodsi et al. (2015) developed a multifunctional biosensor for the simultaneous determination of DA, UA and Try using 2-aminothiazole (AT)/gold nanoparticles (AuNPs) functionalised multiwalled carbon nanotubes (fMWCNT) modified electrode. The fMWCNT/AuNPs-AT composite modified glassy carbon electrode (GCE) was prepared by electrodeposition of AT and followed by electrodeposition of AuNPs and drop casting of fMWCNT on GCE. The formation of the composite was confirmed by atomic force microscopy, scanning electron microscopy and electrochemical studies. The f-MWCNT/AuNPs-AT modified GCE exhibits good electrocatalytic ability for the simultaneous determination of DA, UA and Try. $\mathrm{CV}$ and linear sweep voltammetry were used for simultaneous and selective determination of DA, UA and Try. Moreover, the modified electrode also provides good sensitivity and selectivity for the determination of DA, UA and Try.

Erkal et al. (2016) described the development of a novel biosensor for simultaneous determination of dopamine, uric acid, and folic acid by carbon paste electrode modified by hemoglobin which is electrostatically immobilised on silica-coated magnetic nanoparticles and MWCNTs. The modified carbon paste electrode provided a sensitive and stable biosensor for simultaneous determination of dopamine, uric acid, and folic acid whose performance is much better than those of many previously reported sensors. The detection limits were calculated to be about $12 \mathrm{nM}, 14 \mathrm{nM}$ and $18 \mathrm{nM}$ and the linear range for determination of DA, UA and FA are 1-30.6 $\mu \mathrm{M}, 1-286 \mu \mathrm{M}$ and 1$369 \mu \mathrm{M}$, for dopamine, uric acid, and folic acid, respectively. Finally, the applicability of the proposed biosensor was verified by DA evaluation in serum samples.

\section{Metal ions Biosensing}

The presence of metal ions in food chains due to the rapid industrialisation poses serious threat to the environment. They have severe environmental and medical effects and so require careful monitoring, fast, accurate and reliable analytical techniques for their detection in environment and food. The heavy metal ions, especially $\mathrm{Cd}^{2+}, \mathrm{Pb}^{2+}$ and $\mathrm{Hg}^{2+}$, show extremely hazard to the environment and human being. Electrochemical technique featured with short analytical time, low power cost, high sensitivity and easy adaptability for in-situ measurement is one of the most developed analytical methods used in detection of metal ions in environment and food.

Heavy metal ions are non-biodegradable and contaminate most of the natural resources occurring in the environment including water. Some of the heavy metals including Lead $(\mathrm{Pb})$, Mercury $(\mathrm{Hg})$, Arsenic (As), Chromium (Cr) and Cadmium (Cd) are considered to be highly toxic and hazardous to human health even at trace levels. The development of a sensitive and selective detection method is important to both the environmental and food chemists. Detection and monitoring of metals ions contamination are gaining more attention nowadays but the current analytical methods for the detection of metal ions contamination are very expensive, tedious and can only be handled by trained personnel (Saidur et al., 2017). Various research groups have fabricated $\mathrm{CNT}$ based metal ion biosensor:

Ebrahimi et al. (2017) reported an electrochemical DNA biosensor based on a Gquadruplex $(\mathrm{G} 4)$ for the sensitive determination of $\mathrm{Pb}^{2+}$ using a carbon paste electrode $(\mathrm{CPE})$ or a multi-walled carbon nanotube paste electrode (MWCNTPE) as working electrodes, ethyl green (EG) as a new G4 intercalator, and a singlestranded nucleic acid sequence rich in guanine $(G)$ as DNA probe. Electrochemical determination of $\mathrm{Pb}^{2+}$ relied on probe structural changes from single - stranded to the stabilized intramolecular G4 in the presence of $\mathrm{Pb}^{2+}$, which caused a change in the current of the EG reduction peak due to the intercalation of EG into the G4 structure. The change in the reduction peak of EG before and after its intercalation into the stabilized $\mathrm{G} 4(\Delta \mathrm{I})$ had a linear correlation to the concentration of $\mathrm{Pb}^{2+}$ ions. The linear ranges of $4.0 \times 10^{-10}-5.0 \times 10^{-9} \mathrm{M}$ and $2 \times 10^{-7}-1 \times 1^{-5} \mathrm{M}$ with a detection limit (LOD) of $1.04 \times 10^{-10} \mathrm{M}$ were obtained using $\mathrm{CPE}$, while improved linear ranges of $4.0 \times 10^{-11}-1.0 \times 10^{-9} \mathrm{M}$ and $2 \times 10^{-7}-1 \times 10^{-5} \mathrm{M}$ with a lower LOD of $2.64 \times 10^{-11} \mathrm{M}$ were achieved using the MWCNTPE biosensor. The biosensors exhibited 
satisfactory results in terms of selectivity and practical applicability in the analysis of real samples.

Tian et al. (2016) described a simple one-step electrodeposition method to fabricate three dimensional ordered macroporous chitosan-prussian blue-single walled carbon nanotubes (3DOM CS-PB-SWCNTs) film onto the gold electrode surface to fabricate a copper ion $\left(\mathrm{Cu}^{2+}\right)$-specific DNAzyme biosensor. The new sensing strategy for sensitive and selective detection of $\mathrm{Cu}^{2+}$ was based on $\mathrm{Au}$ nanorods (AuNRs) as signal amplification labels. The electrochemical signal of glucose increased with the concentration of $\mathrm{Cu}^{2+}$ increasing. The morphologies and electrochemistry of the composites were investigated by using SEM, TEM and electrochemical techniques including $\mathrm{CV}$ and EIS and so on. Linear correlations of copper ion concentration were obtained in the range from $10^{-18}$ $\mathrm{M}$ to $10^{-5} \mathrm{M}$, achieving with a limit of detection of $10^{-19} \mathrm{M} \quad(\mathrm{S} / \mathrm{N}=3)$. Parameters affecting the biosensor response such as temperature, the cleavage time and the time of hybridisation were optimized. This biosensor showed a wide range, low detection limit, good reproducibility and high stability. Additionally, these striking properties endow the biosensor with a great promise for analytical applications.

Camara et al. (2016) reported the tuning of a fast, disposable, and label-free biosensor for quantification of iron (III) in food liquid samples such as wine. The biosensor is based on a field effect transistor (FET) where a network of SWCNTs acts as the conductor channel, constituting carbonnanotubes field effect transistors (CNTFETs). An antibody such as transferrin with two specific high-affinity iron (III) binding sites, directly adsorbed to SWCNTs, was used as immunoreaction. Several individual CNTFETs were tested showing a linear range between 0.05 and $2 \mathrm{ng} \mathrm{mL}$ and a limit of

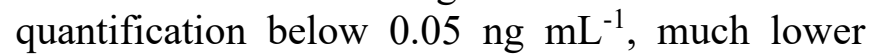
than previously reported analytical techniques. The mean coefficient of variation was $0.13 \%$ showing a low variability of the analytical response. On the other hand, it was not observed interference effect of zinc (II) ion at least until 1:4 iron-zinc ratio.
Finally, recovery percentages of spiked wine samples were around $100 \%$, showing the high accuracy of method.

\section{Pesticides Biosensing}

Organophosphate compounds (OP) are heavily used in agriculture and military activities, while non-organophosphate pesticides are mostly used in agriculture and home defence.

Organophosphorus (OP) compounds are used as pesticides and chemical warfare agents. Hence the detection of OP neurotoxins is essential for the protection of water resources and food supplies, as well as for monitoring detoxification processes. Several researchers have fabricated CNT based pesticides biosensors:

Bagheri et al. (2016) synthesised a biocompatible nanocomposite including bovine serum albumin (BSA) template $\mathrm{Cu}$ nanoclusters (CuNCs@BSA) and SWCNTmetal to fabricate a highly sensitive electrochemical biosensor for paraoxon as a model of organophosphates. The UV-vis, fluorescence and Fourier transform infrared (FTIR) demonstrated that BSA entrapped in the nanocomposite film have been changed in its secondary structure so that it provided an enzyme like activity attributing to the high electrical conductivity of the entrapped copper nanoclusters. Also, the morphology and structure of prepared nanocomposites were investigated by TEM and SEM. In the prepared nanocomposite, the CuNCs@BSA found to play as a conductive holder as well as an accumulator of redox active centres on the surface of the electrode, and SWCNT improves the electrocatalytic activity along with conductivity of glassy carbon electrode (GCE) surface. The fabricated biosensor exhibited excellent sensitivity, acceptable stability, fast response, and high electrocatalytic activity toward the reduction of Paraoxon. The reduction peak current vs paraoxon concentration was linear over the range $50 \mathrm{nM}$ to $0.5 \mu \mathrm{M}$ and $0.5-35 \mu \mathrm{M}$, with a limit of detection of $12.8 \mathrm{nM}$. Notable electrocatalytic properties of the developed electrode toward Paraoxon indicated that the nanocomposite possesses a promising potential to fabricate the third generation enzyme-free 
electrochemical biosensors, bioelectronics and state-of-the-art biomedical devices in the future

Zheng et al. (2016) fabricated a new type of organophosphate pesticide (OP) biosensor based on the immobilization of $\mathrm{AChE}$ by cross-linking on a glassy GCE modified with ionic liquid functionalized graphene (IL-GR), $\quad \mathrm{Co}_{3} \mathrm{O}_{4}$ nanoparticles and chitosan $(\mathrm{CHI})$. The introduction of IL-GR and $\mathrm{Co}_{3} \mathrm{O}_{4}$ nanoparticles not only enhanced the surface area of the modified electrode for enzyme immobilisation but also facilitated the electron transfer, resulting in a high sensitivity of the biosensor. The fabrication process of the sensing surface was characterized by cyclic voltammetry $(\mathrm{CV})$ and electrochemical impedance spectroscopy (EIS). For the oxidation of thiocholine, a hydrolysis product of acetylthiocholine, the peak current at the AChE/IL$\mathrm{GR} / \mathrm{Co}_{3} \mathrm{O}_{4} / \mathrm{CHI} / \mathrm{GCE}$ electrode is larger than those at $\mathrm{AChE} / \mathrm{IL}-\mathrm{GR} / \mathrm{CHI} / \mathrm{GCE}$ and $\mathrm{AChE} / \mathrm{Co}_{3} \mathrm{O}_{4} / \mathrm{CHI} / \mathrm{GCE}$ electrodes. A linear relationship between the inhibition percentage (I\%) and logarithm of the concentration of dimethoate was found in the range from $5.0 \times 10^{-12}$ to $1.0 \times 10^{-}$ ${ }^{7} \mathrm{M}$, with a detection limit of $1.0 \times 10^{-13} \mathrm{M}(\mathrm{S} / \mathrm{N}=$ $3)$. The proposed biosensor provided an efficient and promising platform for the immobilization of AChE and exhibited higher sensitivity and acceptable stability for the detection of organophosphate pesticides.

Similarly, Bao et al. (2016) developed a novel biosensor for rapid, sensitive and selective monitoring of p-nitrophenyl substituted organophosphate pesticides (OPs) in aqueous system using a functional nanocomposite which consists of elastin-like-polypeptideorganophosphate hydrolase (ELP-OPH), bovine serum albumin (BSA), titanium dioxide nanofibers $\left(\mathrm{TiO}_{2} \mathrm{NFs}\right)$ and carboxylic acid functionalized multi-walled carbon nanotubes (c-MWCNTs). ELP-OPH was simply purified from genetically engineered Escherichia coli based on the unique phase transition of ELP and thus served as biocatalyst for OPs, while BSA was used to stabilize OPH activity in the nanocomposite. $\mathrm{TiO}_{2} \mathrm{NFs}$ was employed to enrich organophosphates in the nanocomposite due to its strong affinity with phosphoric group in OPs, while
c-MWCNTs was used to enhance the electron transfer in the amperometric detection as well as for covalent immobilization of ELP-OPH. ELP$\mathrm{OPH} / \mathrm{BSA} / \mathrm{TiO}_{2} \mathrm{NFs} / \mathrm{c}-\mathrm{MWCNTs}$ nanocomposites were systematically characterized using field emission scanning electron microscopy (SEM), Raman spectra, Fourier Transform infrared spectroscopy (FTIR) and X-ray Diffraction (XRD). Under the optimized operating conditions, the ELP$\mathrm{OPH} / \mathrm{BSA} / \mathrm{TiO}_{2} \mathrm{NFs} / \mathrm{c}-\mathrm{MWCNTs}$ based biosensor for OPs shows a wide linear range, a fast response (less than $5 \mathrm{~s}$ ) and limits of detection $(\mathrm{S} / \mathrm{N}=3)$ as low as $12 \mathrm{nM}$ and $10 \mathrm{nM}$ for methyl parathion and parathion, respectively. Such excellent sensing performance can be attributed to the synergistic effects of the individual components in the nanocomposite. Its further application for selectively monitoring OPs compounds spiked in lake water samples was also demonstrated with good accuracy. These features indicate that the developed nanocomposite offers an excellent biosensing platform for rapid, sensitive and selective detection of organophosphates compounds.

Bolat et al. (2017) fabricated a novel amperometric bienzymatic biosensor based on iron (II, III) oxide nanoparticles ( $\mathrm{Fe}_{3} \mathrm{O}_{4} \mathrm{NPs}$ ), MWCNTs and chitosan (CS) modified glassy carbon electrode (GCE) for the determination of acetylcholine (ACh). The CS was used to immobilize AChE and choline oxidase (ChOx). The nanocomposites of Fe3O4NPs and MWCNTs were characterised by SEM, EIS and CV. The electrochemical measurements were based on the detection of enzymatically produced $\mathrm{H}_{2} \mathrm{O}_{2}$. The experimental parameters such as working potential, enzyme unit, $\mathrm{pH}$ and temperature were optimised. The linear ranges of the biosensor were $0.02 \mu \mathrm{mol} \mathrm{L}^{-1}$ $0.111 \mu \mathrm{mol} \mathrm{L}^{-1} \quad$ and $\quad 0.111 \mu \mathrm{mol} \mathrm{L}^{-1}$ $1.87 \mu \mathrm{mol} \mathrm{L}{ }^{-1}$. The detection limit was calculated as $0.61 \mathrm{nmol} \mathrm{L}^{-1}$. In addition, the amperometric biosensor showed high sensitivity, good selectivity, repeatability, reproducibility and long-term stability. The fabricated biosensor was used to determine ACh levels in serum samples.

Miao et al. (2016) designed and developed a novel and highly sensitive electrochemiluminescence (ECL) biosensing 
system for individual detection of different OPs in food samples. Bimetallic Pt-Au nanoparticles were electrodeposited on MWNTs-modified GCE to increase the surface area of electrode and ECL signals of luminol. Biocomposites of enzymes from AChE and ChOx were immobilised onto the electrode surface to produce massive $\mathrm{H}_{2} \mathrm{O}_{2}$, thus amplifying ECL signals. Under optimised experimental conditions, the ECL intensity decreased accordingly with the increase in concentration of OPs, and the inhibition rates of OPs were proportional to their concentrations in the range of $0.1-50 \mathrm{nmol} \mathrm{L}^{-1}$ for malathion, methyl parathion and chlorpyrifos, with detection limit of $0.16 \mathrm{nmol} \mathrm{L}^{-1}, 0.09 \mathrm{nmol} \mathrm{L}^{-1}$ and $0.08 \mathrm{nmol} \mathrm{L}^{-1}$, respectively. The linearity range of the biosensor for pesticide dufulin varied from 50 to $500 \mathrm{nmol} \mathrm{L}^{-1}$, with the detection limit of $29.7 \mathrm{nmol} \mathrm{L}^{-1}$. The resulting biosensor was further validated by assessment of OPs residues in cabbage, which showed a fine applicability for the detection of OPs in the realistic sample.

\section{Conclusions and Perspective}

This review addresses the progress that have been made using CNTs for electrochemical biosensing. CNTs have the ability to strongly interact with biomolecules. Advantages of CNTs lie in their flexible processability to immobilise biomolecules and create multi-functional materials. The excellent electrochemical properties of CNTs enable direct electrochemistry of biomolecules, especially in case of deeply embedded redox active sites. Hence, CNT-based biosensors can work at low operational potential. The high electroactive area of the CNTs, the surface concentration of biomolecules is increased and the amperometric response often exhibits high current density. But metallic impurities are a major obstacle in electrochemical sensing research with CNTs.

The recent advances reveal that applications of CNTs electrodes will face many challenges in the future, in particular in the engineering of bioelectronics interfaces for the fabrication of nano-bioelectrode arrays or biofuel cells. The future challenge will be a multi-faceted challenging work that needs mutual cooperation between material scientist, chemist and engineers who are committed to the fabrication of future micro/nano biosensor

\section{References}

Abdalhai, M. H., Fernandes, A. M., Xia, X., Musa, A., Ji, J. \& Sun, X. (2015). Electrochemical Genosensor To Detect Pathogenic Bacteria (Escherichia coli O157:H7) As Applied in Real Food Samples (Fresh Beef) To Improve Food Safety and Quality Control. Journal of Agricultural and Food Chemistry 63(20), 50175025.

Abdel-Hamid, R. \& Newair, E. F. (2016). AbdelHamid, R., \& Newair, E. F. (2016). Electrochemical behavior of antioxidants: Part 3. Electrochemical studies of caffeic Acid-DNA interaction and DNA/carbon nanotube biosensor for DNA damage and protection Arabian Journal of Chemistry 9 (3), 365-370.

Adhikari, B. R., Govindhan, M. \& Chen, A. (2015). Carbon Nanomaterials Based Electrochemical Sensors/Biosensors for the Sensitive Detection of Pharmaceutical and Biological Compounds. Sensors 15 (9), 2249022508.

Adhikari, B. R., Schraft, H. \& Chen, A. (2017). A high-performance enzyme entrapment platform facilitated by a cationic polymer for the efficient electrochemical sensing of ethanol. Analyst 142 (14), 2595-2602.

Ahmadraji, T. \& Killard, A. J. (2016).

Measurement of total cholesterol using an enzyme sensor based on a printed hydrogen peroxide electrocatalyst. Analytical Methods 8 (13): 2743-2749.

Alam, A. U., Qin, Y., Howlader, M. M. R., Hu, N.X. \& Deen, M. J. (2018). Electrochemical sensing of acetaminophen using multi-walled carbon nanotube and $\beta$-cyclodextrin. Sensors and Actuators B: Chemical 254, 896-909.

Ali, J., Kumar, A., Husain, S., Parveen, S., Khan, Harsh, S. K. \& Husain, M. (2014). FieldEmission Study of Carbon Nanotubes Grown by Low Pressure Chemical Vapour Deposition on Single and Dual Layer of Catalyst. Physics of 
Semiconductor Devices: 17th International Workshop on the Physics of Semiconductor Devices 2013. Jain, V. K. \& Verma. A. Cham, Springer International Publishing: 527-529. Alpat, S., Özdemir, K. \& Kilinç A. S. (2016). Voltammetric Determination of Epinephrine in Pharmaceutical Sample with a Tyrosinase Nanobiosensor Journal of Sensors. 2016, 1-9 Alshehri, R., Ilyas, A. M., Hasan, A., Arnaout, A. Ahmed, F \& Memic, A. (2016). Carbon Nanotubes in Biomedical Applications: Factors, Mechanisms, and Remedies of Toxicity. Journal of Medicinal Chemistry 59 (18), 8149-8167.

Amatatongchai, M., Sroysee, W., Chairam, S. \&. Nacapricha, D. (2017). Amperometric flow injection analysis of glucose using immobilized glucose oxidase on nano-composite carbon nanotubes-platinum nanoparticles carbon paste electrode. Talanta 166, 420-427.

Anojčić, J., Guzsvány, V., Vajdle, O., Madarász, D., Rónavári, A., Kónya, Z. \& Kalcher, K. (2016). Hydrodynamic chronoamperometric determination of hydrogen peroxide using carbon paste electrodes coated by multiwalled carbon nanotubes decorated with $\mathrm{MnO}_{2}$ or $\mathrm{Pt}$ particles. Sensors and Actuators, B: Chemical 233, 83-92.

Arduini, F., Cinti, S., Scognamiglio, V. \& D. Moscone, D. (2016). Nanomaterials in electrochemical biosensors for pesticide detection: advances and challenges in food analysis. Microchimica Acta 183 (7), 20632083.

Ashby, J. N. \& Ramasamy R. P. (2015). Molecularly Tethered Cholesterol Oxidase on Multiwall Carbon Nanotubes for Indirect Detection of Cholesterol. ECS Transactions, 69(41), 1.

Ates, M., Eker, A. A. \& Eker, B. (2017). Carbon nanotube-based nanocomposites and their applications. Journal of Adhesion Science and Technology 31(18), 1977-1997.

Atta, N. F., Abdel Gawad, S. A., El-Ads, E. H., El-Gohary, A. R. M. \& Galal, A. (2017). A new strategy for NADH sensing using ionic liquid crystals-carbon nanotubes/nano-magnetite composite platform. Sensors and Actuators, B: Chemical 251, 65-73.

Baghayeri, M., Amiri, A. \& Farhadi, S. (2016) Development of non-enzymatic glucose sensor based on efficient loading Ag nanoparticles on functionalized carbon nanotubes. Sensors and Actuators, B: Chemical 225, 354-362.

Baghayeri, M. \& Veisi, H. (2015). Fabrication of a facile electrochemical biosensor for hydrogen peroxide using efficient catalysis of hemoglobin on the porous $\mathrm{Pd} @ \mathrm{Fe}_{3} \mathrm{O}_{4}-$ MWCNT nanocomposite. Biosensors and Bioelectronics 74, 190-198.

Bagheri, H., Afkhami, A., Khoshsafar, H., Hajian, A. \& Shahriyari, A. (2016). Protein capped $\mathrm{Cu}$ nanoclusters-SWCNT nanocomposite as a novel candidate of high performance platform for organophosphates enzymeless biosensor. Biosensors and Bioelectronics 89, 829-836.

Bahadır, E. B. \& Sezgintürk, M. K. (2015). Applications of commercial biosensors in clinical, food, environmental, and biothreat/biowarfare analyses. Analytical Biochemistry 478, 107-120.

Bai, J., Sun, C. \& Jiang, X. (2016). Carbon dotsdecorated multiwalled carbon nanotubes nanocomposites as a high-performance electrochemical sensor for detection of $\mathrm{H}_{2} \mathrm{O}_{2}$ in living cells. Analytical and Bioanalytical Chemistry 408 (17), 4705-4714.

Bai, Z., Zhou, C., Xu, H., Wang, G., Pang, H. \& $\mathrm{Ma}, \mathrm{H}$. (2017). Polyoxometalates-doped $\mathrm{Au}$ nanoparticles and reduced graphene oxide: A new material for the detection of uric acid in urine. Sensors and Actuators, B: Chemical 243, 361-371.

Bandodkar, A. J., Jeerapan, I., You, J. M., R. Nuñez-Flores, R. \& Wang, J. (2016). Highly stretchable fully-printed CNT-based electrochemical sensors and biofuel cells: Combining intrinsic and design-induced stretchability. Nano Letters 16(1), 721-727.

Bao, J., Hou, C., Dong, Q., Ma, X., Chen, J., Huo, D., Yang, M., Galil, K. H. A. E., Chen, W. \& 


\section{Lei, Y. (2016). ELP-OPH/BSA/TiO2} nanofibers/c-MWCNTs based biosensor for sensitive and selective determination of $\mathrm{p}$ nitrophenyl substituted organophosphate pesticides in aqueous system. Biosensors and Bioelectronics 85, 935-942.

Barsan, M. M. \& Brett, C. M. A. (2016) Recent advances in layer-by-layer strategies for biosensors incorporating metal nanoparticles. TrAC - Trends in Analytical Chemistry 79, 286296.

Barsan, M. M., Ghica, M. E. \& Brett, C. M. A. (2015). Electrochemical sensors and biosensors based on redox polymer/carbon nanotube modified electrodes: a review. Analytica Chimica Acta 881, 1-23.

Bensghaïer, A., Lau S. T., Seydou, M., Lamouri, A., Leroy, E., Mičušik, M., Forro, K., Beji, M., Pinson, J., Omastová, M. \& Chehimi, M. M. (2017). Efficient covalent modification of multiwalled carbon nanotubes with diazotized dyes in water at room temperature. Langmuir 33(27), 6677-6690.

Bolat, E. Ö., Tı̆̆g, G. A. \& Pekyardımcı, Ş. (2017). Fabrication of an amperometric acetylcholine esterase-choline oxidase biosensor based on MWCNTs-Fe3O4NPs-CS nanocomposite for determination of acetylcholine. Journal of Electroanalytical Chemistry 785, 241-248.

Borisova, B., Sánchez, A., Jiménez-Falcao, S., Martín, M., Salazar, P., Parrado, C., Pingarrón, J. M. \& Villalonga, R. (2016). Reduced graphene oxide-carboxymethylcellulose layered with platinum nanoparticles/PAMAM dendrimer/magnetic nanoparticles hybrids. Application to the preparation of enzyme electrochemical biosensors. Sensors and Actuators B: Chemical 232, 84-90.

Braga, G. B., de Giarola. J. F., de Oliveira, F. M., Ribeiro, E. S., Tarley, C. R. T \& Pereira, A. C. (2015). Development of a Biosensor-Based Carbon Nanotube Paste (MWCT) -Modified DNA Adsorbed on Inorganic Material for the Phenothiazine Determination. New Developments in Analytical Chemistry Research. 139-167.
Buber, E., Yuzer, A., Soylemez, S., Kesik, M., Ince, M. \& Toppare, L. (2017). Construction and amperometric biosensing performance of a novel platform containing carbon nanotubeszinc phthalocyanine and a conducting polymer. International Journal of Biological Macromolecules 96, 61-69.

Budhathoki-Uprety, J., Langenbacher, R. E., Jena, P. V., Roxbury, D. \& Heller, D. A. (2017). A carbon nanotube optical sensor reports nuclear entry via a noncanonical pathway. ACS Nano 11(4), 3875-3882.

Caglayan, M. O. (2017). Electrochemical aptasensors for early cancer diagnosis: a review. Current Analytical Chemistry 13(1), 18-30.

Cámara-Martos, F., Da Costa, J., Justino, C. I. L., Cardoso, S. Duarte, A. C. \& Rocha-Santos, T. (2016). Disposable biosensor for detection of iron (III) in wines. Talanta, 154: 80-84.

Campuzano, S., Pedrero, M., Nikoleli, G. P., Pingarrón, J. M. \& Nikolelis, D. P. (2017). Hybrid 2D-nanomaterials-based electrochemical immunosensing strategies for clinical biomarkers determination. Biosensors and Bioelectronics, 89, 269-279.

Cavallini, A., Boero, C., De Micheli, G. \& Carrara, S. (2015). CNT and proteins for bioelectronics in personalized medicine. Handbook of Bioelectronics: Directly Interfacing Electronics and Biological Systems, 109-121.

Cernat, A., Tertiş, M., Săndulescu, R., Bedioui, F., Cristea, A. \& Cristea, C. (2015).

Electrochemical sensors based on carbon nanomaterials for acetaminophen detection: A review. Analytica Chimica Acta, 886: 16-28.

Chandra, P. (2016). Nanobiosensors for personalized and onsite biomedical diagnosis. The Institution of Engineering and Technology.

Chatterjee, J., Cardenal, J \& Shellikeri, A. (2015). Engineered Carbon Nanotube Buckypaper: A Platform for Electrochemical Biosensors. Journal of Biomedical Nanotechnology 11(1), 150-156.

Chauhan, N., Chawla, S., Pundir, C. S. \& Jain, U (2017). An electrochemical sensor for detection of neurotransmitter-acetylcholine using metal 
nanoparticles, 2D material and conducting polymer modified electrode. Biosensors and Bioelectronics 89, 377-383.

Chen, D., Liu., Z., Fu, J., Guo, Y., Sun, X., Yang, Q \& Wang, X. (2017). Electrochemical acetylcholinesterase biosensor based on multiwalled carbon nanotubes/dicyclohexyl phthalate modified screen-printed electrode for detection of chlorpyrifos. Journal of Electroanalytical Chemistry 801, 185-191.

Chen, J., Yu, C., Zhao, Y., Niu, Y., Zhang, L., Yu, Y., Wu, J. \& He, J. (2017). A novel noninvasive detection method for the FGFR3 gene mutation in maternal plasma for a fetal achondroplasia diagnosis based on signal amplification by hemin

MOFs/PtNPs. Biosensors and Bioelectronics 91, 892-899.

Chen, R., Fioroni, G., McPeak, H., Hahn, C. E. W. $\&$ Farmery, A. D. (2017). Chariacteristics of carbon nanotube based nanocomposite oxygen sensing matrices. In 2016 IEEE Sensors. 1-3. IEEE.

Chiorcea-Paquim, A.-M., Oliveira, S. C. B., Diculescu, V. C. \& Oliveira-Brett, A. M (2017). Applications of DNA-electrochemical biosensors in cancer research. Comprehensive Analytical Chemistry, 77, 287-336.

Choi, T., Kim, S. H., Lee, C. W., Kim, H., Choi, S. K., Kim, S. H., Kim, E., Park, J. \& Kim, H (2015). Synthesis of carbon nanotube-nickel nanocomposites using atomic layer deposition for high-performance non-enzymatic glucose sensing. Biosensors and Bioelectronics 63, 325330.

Correa, D. S., Pavinatto, A., Mercante, L. A., Mattoso, L. H. C., Oliveira, J. E. \& R/iul Jr A. (2017). Chemical sensors based on hybrid nanomaterials for food analysis A2 Grumezescu, Alexandru Mihai. Nanobiosensors, Academic Press, 205-244.

Costa, M. P., Frías, I. A. M., Andrade, C. A. S. \& Oliveira, M. D. L. (2017). Impedimetric gene assay for BCR/ABL transcripts in plasmids of patients with chronic myeloid leukemia. Microchimica Acta, 185(9), 415.

Cui, L., Li, Y., Lu, M., Tang, B. \& Zhang, C.-y. (2018). An ultrasensitive electrochemical biosensor for polynucleotide kinase assay based on gold nanoparticle-mediated lambda exonuclease cleavage-induced signal amplification. Biosensors and Bioelectronics 99, 1-7.

Cui, L., Wu, J. \& H. Ju, H. (2015). Electrochemical sensing of heavy metal ions with inorganic, organic and bio-materials. Biosensors and Bioelectronics 63, 276-286.

Cui, X., Liu, J., Yang, A., Fang, X., Xiao, C., Zhao, Ren, H. \& Li, Z. (2017). The synthesis of polyamidoamine modified gold nanoparticles/SnO2/graphene sheets nanocomposite and its application in biosensor. Colloids and Surfaces A: Physicochemical and Engineering Aspects 520, 668-675.

Dagar, K. \& Pundir, C. S. (2017). An improved amperometric L-lactate biosensor based on covalent immobilization of microbial lactate oxidase onto carboxylated multiwalled carbon nanotubes/copper nanoparticles/polyaniline modified pencil graphite electrode. Enzyme and Microbial Technology 96: 177-186.

Dalkıran, B., Erden, P. E. \& Kılıç, E. (2017). Amperometric biosensors based on carboxylated multiwalled carbon nanotubesmetal oxide nanoparticles-7, 7, 8, 8tetracyanoquinodimethane composite for the determination of xanthine. Talanta 167, 286295.

Deb, A. K., Das, S. C., Saha, A., Wayu, M. B., Marksberry, M. H., Baltz, R. J., \& Chusuei, C. C. (2016). Ascorbic acid, acetaminophen, and hydrogen peroxide detection using a dendrimerencapsulated Pt nanoparticle carbon nanotube composite. Journal of Applied Electrochemistry 46(3), 289-298.

Dervisevic, E., Dervisevic, M., Nyangwebah, J. N., \& Şenel, M. (2017). Development of novel amperometric urea biosensor based on FcPAMAM and MWCNT bio-nanocomposite film. Sensors and Actuators, B: Chemical 246, 920-926. 
Dervisevic, M., Dervisevic, E. \& Şenel, M. (2018). Design of amperometric urea biosensor based on self-assembled monolayer of cystamine/PAMAM-grafted MWCNT/Urease. Sensors and Actuators, B: Chemical 254, 93101.

Dönmez G. Ç., Şeker, Ş., Elçin, A. E. \& Elçin, Y. M. (2017). A comparative study on the in vitro cytotoxic responses of two mammalian cell types to fullerenes, carbon nanotubes and iron oxide nanoparticles. Drug and Chemical Toxicology 40 (2), 215-227.

Dramińska, S. \& Bilewicz, R. (2017). Bienzymatic mediatorless sensing of total hydrogen peroxide with catalase and multi-copper enzyme coadsorbed at carbon nanotube-modified electrodes. Sensors and Actuators, B: Chemical 248, 493-499.

Ebrahimi, M., Raoof, J. B. \& Ojani, R. (2017). Design of a novel electrochemical biosensor based on intramolecular G-quadruplex DNA for selective determination of lead (II) ions. Analytical and Bioanalytical Chemistry 409 (20), 4729-4739.

Eguílaz, M., Gutiérrez, A., Gutierrez, F., GonzálezDomínguez, J. M., Ansón-Casaos, A., Hernández-Ferrer, J., Ferreyra, N. F., Martínez, M. T. \& Rivas, G. (2016). Covalent functionalization of single-walled carbon nanotubes with polytyrosine: characterization and analytical applications for the sensitive quantification of polyphenols. Analytica Chimica Acta 909, 51-59.

Eguílaz, M., Gutiérrez, A. \& Rivas, G. (2016). Noncovalent functionalization of multi-walled carbon nanotubes with cytochrome c: enhanced direct electron transfer and analytical applications. Sensors and Actuators, B: Chemical 225, 74-80.

Eguílaz, M., Gutierrez, F., Gnzález-Domínguez, J. M. Martínez, M. T \& G. Rivas, G. (2016). Single-walled carbon nanotubes covalently functionalized with polytyrosine: a new material for the development of NADH-based biosensors. Biosensors and Bioelectronics 86, 308-314.

Eguílaz, M., Venegas, C. J., Gutiérrez, A., Rivas, G. A. \& Bollo, S. (2016). Carbon nanotubes non- covalently functionalized with cytochrome c: A new bioanalytical platform for building bienzymatic biosensors. Microchemical Journal 128: 161-165.

Emami M. A., \& Haghjoo, S. (2014). Amperometric urea biosensor based on covalently immobilized urease on an electrochemically polymerized film of polyaniline containing MWCNTs. Synthetic Metals 194: 1-6.

Erden, P. E., Kaçar, C., Öztürk, F. \& Kiliç, E. (2015). Amperometric uric acid biosensor based on poly (vinylferrocene)-gelatin-carboxylated multiwalled carbon nanotube modified glassy carbon electrode. Talanta 134: 488-495.

Erkal, A., Aşik, I., Yavuz, S. Kariper, A. \& Üstündał Z. (2016). Biosensor application of carbonaceous nanocoil material: preparation, characterization, and determination of dopamine and uric acid in the presence of ascorbic acid. Journal of the Electrochemical Society 163 (5), H269-H277.

Ertek, B. \& Dilgin, Y. (2016). Photoamperometric flow injection analysis of glucose based on dehydrogenase modified quantum dots-carbon nanotube nanocomposite electrode. Bioelectrochemistry 112, 138-144.

Fu, X., Cui, X., Wei, X. \& Ma, J. (2014). Investigation of low and mild temperature for synthesis of high quality carbon nanotubes by chemical vapor deposition. Applied Surface Science 292, 645-649.

Fu, Y., Romay, V., Liu, Y., Ibarlucea, B., Baraban, L., Khavrus, V., Oswald, S., Bachmatiuk, A., Ibrahim, I. Rümmeli, M., Gemming, T., Bezugly, V. \& Cuniberti, G. (2017). Chemiresistive biosensors based on carbon nanotubes for label-free detection of DNA sequences derived from avian influenza virus H5N1. Sensors and Actuators B: Chemical 249, 691-699.

Ghodsi, J., Hajian, A., Rafati, A. A., Shoja, Y., Yurchenko, O. \& Urban, G. (2016). Electrostatically immobilized hemoglobin on silica-coated magnetic nanoparticles for simultaneous determination of dopamine, uric acid, and folic acid. Journal of the Electrochemical Society 163(13), B609-B616. 
Ghodsi, J., Rafati, A. A., Shoja, Y. \& Najafi, M. (2015). Determination of dopamine in the presence of uric acid and folic acid by carbon paste electrode modified with $\mathrm{CuO}$ nanoparticles/hemoglobin and multi-walled carbon nanotube. Journal of the Electrochemical Society 162(4), B69-B74.

Gholivand, M. B. \& Khodadadian, M. (2014). Amperometric cholesterol biosensor based on the direct electrochemistry of cholesterol oxidase and catalase on a graphene/ionic liquid-modified glassy carbon electrode. Biosensors and Bioelectronics 53, 472-478.

Gokoglan, T. C., Soylemez, S., Kesik, M., Dogru, I. B., Turel, O., Yuksel, R., Unalan, H. E. \& Toppare, L.(2017). A novel approach for the fabrication of a flexible glucose biosensor: The combination of vertically aligned CNTs and a conjugated polymer. Food Chemistry 220: 299305.

Gougis, M., Tabet-Aoul, A., D. Ma, D. \& Mohamedi, M. (2014). Laser synthesis and tailor-design of nanosized gold onto carbon nanotubes for non-enzymatic electrochemical glucose sensor. Sensors and Actuators B: Chemical 193(0): 363-369.

Gu, C. J., Kong, F. Y., Chen, Z. D., Fan, D. H., Fang, H. L. \& Wang, W. (2016). Reduced graphene oxide-Hemin-Au nanohybrids: Facile one-pot synthesis and enhanced electrocatalytic activity towards the reduction of hydrogen peroxide. Biosensors and Bioelectronics 78, 300-307.

Gui, R., Jin, H., Guo, H. \& Wang, Z. (2018). Recent advances and future prospects in molecularly imprinted polymers-based electrochemical biosensors. Biosensors and Bioelectronics 100, 56-70.

Güner, A., Çevik, E., Şenel, M. \& Alpsoy, L (2017). An electrochemical immunosensor for sensitive detection of Escherichia coli O157: H7 by using chitosan, MWCNT, polypyrrole with gold nanoparticles hybrid sensing platform. Food Chemistry 229: 358-365.

Guo, Y., Wang, Y., Liu, S., Yu, J., Wang, H., Cui, M. \& Huang, J. (2015). Electrochemical immunosensor assay (EIA) for sensitive detection of E. coli O157: H7 with signal amplification on a SG-PEDOT-AuNPs electrode interface. Analyst 140(2), 551-559.

Gupta, S., Murthy,S C. N. \& Prabha, C. R. (2018). Recent advances in carbon nanotube based electrochemical biosensors. International Journal of Biological Macromolecules 108, 687703.

Guzsvány, V., Anojčić, J., Radulović, E., Vajdle, O., Stanković, I., Madarász, D., Kónya, Z. \& Kalcher, K. (2017). Screen-printed enzymatic glucose biosensor based on a composite made from multiwalled carbon nanotubes and palladium containing particles. Microchimica Acta 184(7), 1987-1996.

Hamidi, H. \& Haghighi, B. (2016). Fabrication of a sensitive amperometric sensor for NADH and $\mathrm{H} 2 \mathrm{O} 2$ using palladium nanoparticlesmultiwalled carbon nanotube nanohybrid. Materials Science and Engineering C 62, 423428.

Han, J., Li, Y., Feng, J., Li, M., Wang, P., Chen, Z., \& Dong, Y. (2017). A novel sandwich-type immunosensor for detection of carcinoembryonic antigen using silver hybrid multiwalled carbon nanotubes/manganese dioxide. Journal of Electroanalytical Chemistry 786, 112-119.

Han, L., Tao, H., Huang, M., Zhang, Y., Qiao, S. \& Shi, R. (2016). A hydrogen peroxide biosensor based on multiwalled carbon nanotubespolyvinyl butyral film modified electrode. Russian Journal of Electrochemistry 52 (2), 115122.

Hasanzadeh, M., Shadjou, N., Lin, Y. \& de la Guardia, M. (2017). Nanomaterials for use in immunosensing of carcinoembryonic antigen (CEA): Recent advances. TrAC - Trends in Analytical Chemistry 86, 185-205.

He, J., Sunarso, J., Zhu, Y., Zhong, Y., Miao, J., Zhou, W \& Shao, Z. (2017). High-performance non-enzymatic perovskite sensor for hydrogen peroxide and glucose electrochemical detection. Sensors and Actuators, B: Chemical 244, 482-491.

He, Y., Yang, X., Han, Q. \& Zheng, J. (2017). The investigation of electrochemistry behaviours of tyrosinase based on directly-electrodeposited 
grapheneon choline-gold nanoparticles. Molecules 22(7). 1047

Hien, H. T., Giang, H. T., Trung, T. \& Van-Tuan, C. (2017). Enhancement of biosensing performance using a polyaniline/multiwalled carbon nanotubes nanocomposite. Journal of Materials Science 52(3), 1694-1703.

Hossain, M. F., Heo, M., Shin \& J. H., Park, J. Y. (2015). An Electrochemical Enzymatic Biosensor Based on Au/FGs/sol-gel-GOx Composite/Nafion. International Journal of Electrochemical Science 10(8), 6803-6819.

Huang, J., Yue, G., Yang, J., Bai, S., Hu, Q. \& Wang, L. (2017). Design, synthesis and application of carboxylic multi-walled carbon nanotubes/tetrahexahedral platinum nanocrystals nanocomposites biosensor for simultaneous determination of guanine and adenine in DNA. Journal of Electroanalytical Chemistry 801, 536-544.

Hui, Y., Ma, X., Hou, X., Chen, F. \& Yu, J (2015). Silver nanoparticles- $\beta$-cyclodextrin-graphene nanocomposites based biosensor for guanine and adenine sensing. Ionics 21(6), 1751-1759.

Jain, A., Homayoun, A., Bannister, C. W. \& Yum, K. (2015). Single-walled carbon nanotubes as near-infrared optical biosensors for life sciences and biomedicine. Biotechnology Journal 10(3), 447-459.

Jain, U., Narang, J. \& Chauhan, N. (2016).

Enhanced electrochemical performance of xanthine biosensor by core - shell magnetic nanoparticles and carbon nanotube interface. Advanced Materials Letters 7(6): 472-479.

Jaiswal, N. \& Tiwari, I. (2017). Recent build outs in electroanalytical biosensors based on carbonnanomaterial modified screen printed electrode platforms. Analytical Methods 9(26): 38953907.

Janegitz, B. C., Cancino, J. \& Zucolotto, V. (2014). Disposable biosensors for clinical diagnosis. Journal of Nanoscience and Nanotechnology 14(1), 378-389.

Jasim, A., Ullah, M. W, Shi, Z., Lin, X. \& Yang, G. (2017). Fabrication of bacterial cellulose/polyaniline/single-walled carbon nanotubes membrane for potential application as biosensor. Carbohydrate Polymers 163, 62-69.

Jia, X., Song, T., Liu, Y., Meng, L. \& Mao, X. (2017). An immunochromatographic assay for carcinoembryonic antigen on cotton thread using a composite of carbon nanotubes and gold nanoparticles as reporters. Analytica Chimica Acta 969, 57-62.

Jiang, B., Zhou, K., Wang, C., Sun, Q., Yin, G., Tai, Z., Wilson, K., Zhao, J. \& Zhang, L. (2018). Label-free glucose biosensor based on enzymatic graphene oxide-functionalized tilted fiber grating. Sensors and Actuators $B$ : Chemical 254, 1033-1039.

Kaçar, C., Erden, P. E. \& Kılıç, K. (2017). Amperometric 1-lysine biosensor based on carboxylated multiwalled carbon nanotubes$\mathrm{SnO} 2$ nanoparticles-graphene composite. Applied Surface Science 419, 916-923.

Kangkamano, T., Numnuam, A., Limbut, W., Kanatharana, P. \& Thavarungkul, P. (2017). Chitosan cryogel with embedded gold nanoparticles decorated multiwalled carbon nanotubes modified electrode for highly sensitive flow based non-enzymatic glucose sensor. Sensors and Actuators, B: Chemical 246: 854-863.

Karimi-Maleh, H., Shojaei, A. F., Tabatabaeian, K., Karimi, F., Shakeri, S. \& Moradi, R. (2016). Simultaneous determination of 6mercaptopruine, 6-thioguanine and dasatinib as three important anticancer drugs using nanostructure voltammetric sensor employing Pt/MWCNTs and 1-butyl-3-methylimidazolium hexafluoro phosphate. Biosensors and Bioelectronics 86, 879-884.

Kim, I., Kim, G. H., Kim, C. S., Cha, H. J. \& Lim, G. (2015). Optical detection of paraoxon using single-walled carbon nanotube films with attached organophosphorus hydrolaseexpressed Escherichia coli. Sensors 15(6): 12513-12525.

Kim, J., Jin, J. H., Kim, H. S., Song, W., Shin, S. K., Yi, H., Jang, D. H., Shin, S. \& Lee, B. Y. (2016). Fully automated field-deployable bioaerosol monitoring system using carbon 
nanotube-based biosensors. Environmental Science and Technology 50(10), 5163-5171.

Kitikul, J., Satienperakul, S., Preechaworapun, A., Pookmanee, P. \& Tangkuaram, T. (2017). A simple flow amperometric electrochemical biosensor based on chitosan scaffolds and gold nanowires modified on a glassy carbon electrode for detection of glutamate in food products. Electroanalysis 29(1), 264-271.

Ko, T. H., Radhakrishnan, S., Seo, M. K., Khil, M. S., Kim, H. Y. \& Kim, B. S. (2017). A green and scalable dry synthesis of $\mathrm{NiCo} 2 \mathrm{O} 4 /$ graphene nanohybrids for high-performance supercapacitor and enzymeless glucose biosensor applications. Journal of Alloys and Compounds 696, 193-200.

Koteshwara, K., R., Satyanarayana, M., Goud, K. Y., Gobi, K. V. \& H. Kim, H. (2017). Carbon nanotube ensembled hybrid nanocomposite electrode for direct electrochemical detection of epinephrine in pharmaceutical tablets and urine. Materials Science and Engineering C 79, 93-99.

Kulkarni, T. \& Slaughter, G. (2017). Self-powered glucose biosensor operating under physiological conditions. Proceedings of IEEE Sensors. 1-3.

Lakshmi, G. B. V. S. \& Khan, S. A. (2014). Synthesis of CNTs by arc discharge method in water bath. In Physics of Semiconductor Devices (pp. 601-602). Springer, Cham.

Lawal, A. T. (2016). Synthesis and utilization of carbon nanotubes for fabrication of electrochemical biosensors. Materials Research Bulletin 73, 308-350.

Lawal, A. T. (2018). Progress in utilisation of graphene for electrochemical biosensors. Biosensors and Bioelectronics 106, 149-178.

Lee, M. \& Kim, D. (2016). Non-enzymatic carbohydrates detection based on Au modified MWCNT field-effect transistor. Materials Letters 169, 257-261.

Lee, S. W., Lee, K. Y., Song, Y. W., Choi, W. K., Chang, J. \& Yi, H. (2016). Direct electron transfer of enzymes in a biologically assembled conductive nanomesh enzyme platform. Advanced Materials 28(8), 1577-1584.
Li, H., Wu, J., Melnyczuk, J. M., Olubi, O., Lewis, L. I., Cao, Y., Nagappan, P., Khan, S. A., Ingram, C. W. \& Harruna, I. I. (2015). NanoSnowflower of Gold Nanoparticles-Ruthenium Metallopolymer-Carbon Nanotubes Binding Anti-DNP IgE Antibody. Journal of Nanoscience and Nanotechnology 15(8), 57335740.

Li, J. \& Lee, E. C. (2015). Carbon nanotube/polymer composite electrodes for flexible, attachable electrochemical DNA sensors. Biosensors and Bioelectronics 71, 414419.

Li, Y., Zhang, Y., Han, J., Chu, P. K., Feng, J. \& Dong, Y. (2017). A sensitive non-enzymatic immunosensor composed of silver nanoflowers for squamous cell carcinoma antigen. $R S C$ Advances 7(4), 2242-2248.

Li, Y., Zhao, M., Chen, J., Fan, S., Liang, J., Ding, L. \& Chen, S. (2016). Self-assembled $\mathrm{NiFe} 2 \mathrm{O} 4 /$ carbon nanotubes sponge for enhanced glucose biosensing application. Applied Surface Science 362, 115-120.

Lin, X., Wang, Q., Zhu, S., Xu, J., Xia, Q. \& Fu, Y. (2016). A highly sensitive glutamic acid biosensor based on the determination of NADH enzymically generated by L-glutamic dehydrogenase. RSC Advances 6 (51), 4582945834.

Liu, A., Lang, Q., Liang, B. \& Shi, J. (2017). Sensitive detection of maltose and glucose based on dual enzyme-displayed bacteria electrochemical biosensor. Biosensors and Bioelectronics 87, 25-30.

Liu, K., H. Dong and Y. Deng (2016). Recent advances on rapid detection of pesticides based on enzyme biosensor of nanomaterials. Journal of Nanoscience and Nanotechnology 16(7), 6648-6656.

Liu, N., Nie, D., Tan, Y., Zhao, Z., Liao, Y., Wang, H., Sun, C. \& Wu, A. (2017). An ultrasensitive amperometric immunosensor for zearalenones based on oriented antibody immobilization on a glassy carbon electrode modified with MWCNTs and AuPt nanoparticles. Microchimica Acta 184(1), 147-153.

Liu, W. N., D. Ding, D., Song, Z. L., Bian, X., Nie, X. K., Zhang, X. B., Chen, Z. \& Tan, W. (2014). 
Hollow graphitic nanocapsules as efficient electrode materials for sensitive Hydrogen peroxide detection. Biosensors and Bioelectronics 52, 438-444.

Liu, Y., Deng, Y., Dong, H., Liu, K. \& He, N. (2017). Progress on sensors based on nanomaterials for rapid detection of heavy metal ions. Science China Chemistry 60(3), 329-337.

Liu, Y., Song, T., Jia, X., Meng, L. \& X. Mao, X. (2017). Gold nanoparticles decorated carbon nanotube probe based immunochromatographic assay on cotton thread. Sensors and Actuators, B: Chemical 251, 1112-1118.

Lopes, J. H., Colson, F. X., Barralet, J. E. \& Merle, G. (2017). Electrically wired enzyme/TiO2 composite for glucose detection. Materials Science and Engineering C 76, 991-996.

Lorencova, L., Bertok, T., Dosekova, E., Holazova, A., Paprckova, D., Vikartovska, A., Sasinkova, V., Filip, J., Kasak, P., Jerigova, M., Velic, D., Mahmoud, K. A. \& Tkac, J. (2017). Electrochemical performance of Ti3C2Tx MXene in aqueous media: towards ultrasensitive H2O2 sensing. Electrochimica Acta 235, 471479.

Luo, J., Wan, M., Cui, J., Peng, B., Zhang, Y., Wang, Y., Qin, Y., Zheng, H. \& Wu, Y. (2017). Synthesis of nonstoichiometric CeO2@CNT core/shell nanowire arrays and their applications in biosensing. Materials Letters 188: 275-279.

Luong, J. H. T., Glennon, J. D., Gedanken, A. \& Vashist, S. K. (2017). Achievement and assessment of direct electron transfer of glucose oxidase in electrochemical biosensing using carbon nanotubes, graphene, and their nanocomposites. Microchimica Acta 184(2), 369-388.

Ma, Y., Shen, X. L., Zeng, Q., Wang, H. S. \& Wang, L. S. (2017). A multi-walled carbon nanotubes based molecularly imprinted polymers electrochemical sensor for the sensitive determination of HIV-p24. Talanta 164: 121127.

Magyar, M., Rinyu, L., Janovics, R., Berki, P., Hernádi, K., Hajdu, K., Szabó, T. \& Nagy, L. (2016). Real-Time sensing of hydrogen peroxide by ITO/MWCNT/horseradish peroxidase enzyme electrode. Journal of Nanomaterials 2016, 1-12.

Malhotra, B. D., Srivastava, S., Ali, M. A. \& Singh, C. (2014). Nanomaterial-based biosensors for food toxin detection. Applied Biochemistry and Biotechnology 174(3), 880-896.

Mansouri, N., Babadi, A. A., Bagheri, S. \& Hamid, S. B. A. (2017). Immobilization of glucose oxidase on 3D graphene thin film: novel glucose bioanalytical sensing platform. International Journal of Hydrogen Energy 42(2), 1337-1343.

Medyantseva, E. P., Brusnitsyn, D. V., Varlamova, R. M., Maksimov, A. A., Konovalova, O. A. \& Budnikov, H. C. (2017). Electrically conducting nanobiocomposites using carbon nanotubes and collagen waste fibers. Journal of Analytical Chemistry 72(4), 362-370.

Meiyazhagan, A., S. Thangavel, H. Daniel P, A. Pulickel $M$ and T. Palanisamy (2015). Electrically conducting nanobiocomposites using carbon nanotubes and collagen waste fibers. Materials Chemistry and Physics 157: 815.

Meshram, B. H. (2015). Polypyrrole-CarbonNanotubes lactate oxidase nanobiocompositefilm based modified stainless steel electrode lactate biosensor. Procedia Materials Science 10, 176.-185

Meshram, B. H., Mahore, R. P., Virutkar, P. D. \& Kondawar, S. B. (2015). Polyaniline/MnO2 nanocomposites based stainless steel electrode modified enzymatic urease biosensor. Procedia Materials Science 10: 176-185.

Miao, S. S., Wu, M. S., Ma, L. Y., He, X. J. \& Yang, H. (2016). Electrochemiluminescence biosensor for determination of organophosphorous pesticides based on bimetallic Pt-Au/multi-walled carbon nanotubes modified electrode. Talanta 158: 142-151. Miao, C., Nian, C., Shao, X. \& Chen, Q. (2017). Alcohol biosensor based on multi-walled carbon nanotubes/platinum nanoparticles nanocomposite. Chinese Journal of Sensors and Actuators 30(1), 16-19.

Moretti, E. D. S., De Fátima, J. G., Kuceki, M., Prete, M. C., Pereira, A. C. \& Tarley, C. R. T. 
(2016). Electrochemical sensors based on molecularly imprinted polymers for pharmaceuticals analysis. RSC Advances 6(34), 28751-28760.

Moyo, M., Okonkwo, J. O. \& Agyei, N. M (2014a). An amperometric biosensor based on horseradish peroxidase immobilized onto maize tassel-multi-walled carbon nanotubes modified glassy carbon electrode for determination of heavy metal ions in aqueous solution. Enzyme and Microbial Technology 56, 28-34.

Moyo, M., Okonkwo, J. O. \& Agyei, N. M. (2014b). A label-free electrochemical biosensor for acrylamide based on DNA immobilized on graphene oxide-modified glassy carbon electrode. International Journal of Electrochemical Science 9(3), 1439-1453.

Muguruma, H., Iwasa, H., Hidaka, H., Hiratsuka, A. \& Uzawa, H. (2017). Mediatorless direct electron transfer between flavin adenine dinucleotide-dependent glucose dehydrogenase and single-walled carbon nanotubes. $A C S$ Catalysis 7(1), 725-734.

Mutyala, S. and J. Mathiyarasu (2016). A highly sensitive NADH biosensor using nitrogen doped graphene modified electrodes. Journal of Electroanalytical Chemistry 775, 329-336.

Naghib, S. M. (2016). Fabrication of nafion/silver nanoparticles/reduced graphene nanosheets/glucose oxidase nanobiocomposite for electrochemical glucose biosensing. Analytical and Bioanalytical Electrochemistry 8(4), 453-465.

Nandini, S., Nalini, S., Shanmugam, S., Niranjana, P., Melo, J. S. \& Suresh, G. S. (2014). Rhoeo discolor leaf extract as a novel immobilizing matrix for the fabrication of an electrochemical glucose and hydrogen peroxide biosensor. Analytical Methods 6(3), 863-877.

Narang, J., Malhotra, N., Singhal, C. \& Pundir, C. S. (2017). Evaluation of freshness of fishes using MWCNT/TiO 2 nanobiocomposites based biosensor. Food Analytical Methods 10(2), 522528.

Nenkova, R. D., Ivanov, Y. L. \& Godjevargova, T. I. (2017). Influence of different nanoparticles on electrochemical behavior of glucose biosensor.
In AIP Conference Proceedings (Vol. 1809, No. 1, p. 020037). AIP Publishing LLC..

Ouyang, J., Liu, Z., Han, Y., Zeng, K., Sheng, J., Deng, L. \& Liu, Y. N. (2016). Fabrication of surface protein-imprinted biofuel cell for sensitive self-powered glycoprotein detection. ACS Applied Materials and Interfaces 8(51), 35004-35011.

Ozkan-Ariksoysal, D., Kayran, Y. U., Yilmaz, F. F., Ciucu, A. A., David, I. G., David, V., HosgorLimoncu, M. \& Ozsoz, M. (2017). DNAwrapped multi-walled carbon nanotube modified electrochemical biosensor for the detection of Escherichia coli from real samples. Talanta 166, 27-35.

Paga'n, M., Suazo, D., del Toro, N. \& Griebenow, K. (2014). A comparative study of different protein immobilization methods for the construction of an efficient nano-structured lactate oxidase-SWCNT-biosensor. Biosensors and Bioelectronics 64: 138-146.

Pakapongpan, S. \& Poo-arporn, R. P. (2017). Selfassembly of glucose oxidase on reduced graphene oxide-magnetic nanoparticles nanocomposite-based direct electrochemistry for reagentless glucose biosensor. Materials Science and Engineering C 76: 398-405.

Pan, L. H., Kuo, S. H., Lin, T. Y., Lin, C. W. Fang, P. Y. \& Yang, H. W. (2017). An electrochemical biosensor to simultaneously detect VEGF and PSA for early prostate cancer diagnosis based on graphene oxide/ssDNA/PLLA nanoparticles. Biosensors and Bioelectronics 89, 598-605.

Pandey, A., P. Pandey, O. P. Pandey and N. K. Shukla (2016). Fabrication of Potentiometric Cholesterol Biosensor by Crosslinking of Cholesterol Oxidase and Carbon Nanotubes Modified Cellulose Acetate Membrane. Sensor Letters 14(1): 102-108.

Papa, H., Gaillard, M, Gonzalez, L. \& Chatterjee, J. (2014). Fabrication of functionalized carbon nanotube buckypaper electrodes for application in glucose biosensors. Biosensors 4(4), 449-460.

Paul, B., Panigrahi, A. K., Singh, V. \&. Singh, S. G. (2017). A multi-walled carbon nanotube-zinc oxide nanofiber based flexible chemiresistive 
biosensor for malaria biomarker detection. Analyst 142(12): 2128-2135.

Paul, K. B., Singh, V., Vanjari, S. R. K. \& Singh, S. G. (2017). One step biofunctionalized electrospun multiwalled carbon nanotubes embedded zinc oxide nanowire interface for highly sensitive detection of carcinoma antigen125. Biosensors and Bioelectronics 8, 144-152. Pereira, N. D. M., De Oliveira, F. M., Pereira, N. R., Verly, R. M., Souto, D. E. P., Kubota, L. T., Tanaka, A. A., Damos, F. S \& Luz, R. C. S. (2015). Ultrasensitive biosensor for detection of organophosphorus pesticides based on a macrocycle complex/carbon nanotubes composite and 1-methyl-3-octylimidazolium tetrafluoroborate as binder compound. Analytical Sciences 31(1): 29-35.

Piro, B., Shi, S., Reisberg, S., Noël, V. \& Anquetin, G. (2016). Comparison of electrochemical immunosensors and aptasensors for detection of small organic molecules in environment, food safety, clinical and public security. Biosensors 6(1).

Pisoschi, A. M., A. Pop, A. I. Serban and C. Fafaneata (2014). Electrochemical methods for ascorbic acid determination. Electrochim. Acta 121, 443-460.

Poo-Arporn, R. P., Pakapongpan, S., Khownarumit, P., Waraho-Zhmayev, D., Poo-Arporn, Y. \& Surareungchai, W. (2017). Development of Mevalonic Acid Biosensor Using Amperometric Technique Based on Nanocomposite of Nicotinamide Adenine Dinucleotide and Carbon Nanotubes. Journal of the Electrochemical Society 164(7), B349-B355.

Prakash, M. D., Singh, S. G., Sharma, C. S. \& Krishna, V. S. R. (2017). Electrochemical Detection of Cardiac Biomarkers Utilizing Electrospun Multiwalled Carbon Nanotubes Embedded SU-8 Nanofibers. Electroanalysis 29(2): 380-386.

Punetha, V. D., Rana, S.., Yoo, H. J., Chaurasia, A., McLeskey Jr, J. T., Ramasamy, M. S., Sahoo, N. G. \& Cho, J. W. (2017). Functionalization of carbon nanomaterials for advanced polymer nanocomposites: A comparison study between CNT and graphene. Progress in Polymer Science 67: 1-47.
Qian, J., Yang, X., Yang, Z., Zhu, G., Mao, H. \& Wang, K. (2015). Multiwalled carbon nanotube@ reduced graphene oxide nanoribbon heterostructure: synthesis, intrinsic peroxidaselike catalytic activity, and its application in colorimetric biosensing. Journal of Materials Chemistry B 3(8), 1624-1632.

Qiu, K., Chen, X., Ci, S., Li, W., Bo, Z., Cen, K. \& Wen, Z. (2016). Facile preparation of nickel nanoparticle-modified carbon nanotubes with application as a nonenzymatic electrochemical glucose sensor. Analytical Letters 49(4): 568578.

Qu, F., Ma, X., Hui, Y., Chen, F., Gao, Y. \& Chen, Y. (2017). Surfactant-assisted preparation of nanohybrid for simultaneously improving enzyme-immobilization and electron-transfer in biosensor and biofuel cell. Journal of Solid State Electrochemistry 21(6), 1545-1557.

Ramnani, P., Saucedo, N. M. \& Mulchandani, A. (2016). Carbon nanomaterial-based electrochemical biosensors for label-free sensing of environmental pollutants. Chemosphere 143: 85-98.

Rather, J. A., Pilehvar, S. \& K. De-Wael, K. (2015). Polycyclodextrin and carbon nanotubes as composite for tyrosinase immobilization and its superior electrocatalytic activity towards butylparaben an endocrine disruptor. Journal of Nanoscience and Nanotechnology 15(5), 33653372.

Rawal, R., Chauhan, N., Tomar, M. \& Gupta, V. (2017). A contrivance based on electrochemical integration of graphene oxide nanoparticles/nickel nanoparticles for bilirubin biosensing. Biochemical Engineering Journal 125: 238-245.

Reshetilov, A. N., Plekhanova, Y. V., Tarasov, S. E., Arlyapov, V. A., Kolesov, V. V., Gutorov, M. A, Gotovtsev, P. M. \& Vasilov, R. G. (2017). Applied Biochemistry and Microbiology 53(1), 123-129.

Revathi, S., Vuyyuru, M. \& Dhanaraju, M. D. (2015). Carbon nanotube: a flexible approach for nanomedicine and drug delivery. Asian Journal of Pharmaceutical and Clinical Research 8(1), 25-31. 
Romero-Arcos, M., Garnica-Romo, M. G. \& Martínez-Flores, H. E. (2017). Characterization of amperometric laccase biosensor based on carbon nanotube. Procedia Technology 27, 279281.

Sadrabadi, N. R., Ensafi, A. A., Heydari-Bafrooei, E. \& Fazilati, M. (2016). Screening of food samples for zearalenone toxin using an electrochemical bioassay based on DNAzearalenone interaction. Food Analytical Methods 9(9), 2463-2470.

Sagadevan, S. \& Periasamy, M. (2014). Recent trends in nanobiosensors and their applicationsa review. Reviews on Advanced Materials Science 36(1), 62-69.

Sağlam, Ö. \& Dilgin, Y. (2017). Fabrication of Photoelectrochemical Glucose Biosensor in Flow Injection Analysis System Using ZnS/CdS-Carbon Nanotube Nanocomposite Electrode. Electroanalysis 29(5), 1368-1376.

Saidura, M. R., Abdul-Aziz, A. R. \& Basirun, W. J. (2017). Recent advances in DNA-based electrochemical biosensors for heavy metal ion detection: a review. Biosens. Bioelectron. 90, 125-139.

Sánchez-Tirado, E., Salvo, C., González-Cortés, A., Yáñez-Sedeño, P., Langa, F. \& Pingarrón, J. M. (2017). Electrochemical immunosensor for simultaneous determination of interleukin-1 beta and tumor necrosis factor alpha in serum and saliva using dual screen printed electrodes modified with functionalized double-walled carbon nanotubes. Analytica Chimica Acta 959, 66-73.

Sanzó, G., Tortolini, C., Antiochia, R., Favero, G. \& Mazzei, F. (2015). Development of carbonbased nano-composite materials for direct electron transfer based biosensors. Journal of Nanoscience and Nanotechnology 15(5), 34233428.

Satyanarayana, M., Yugender, K., Koteshwara R. K. \& Vengatajalabathy G, K. (2017). Conducting Polymer-Layered Carbon Nanotube as Sensor Interface for Electrochemical Detection of Dacarbazine InVitro. Electrocatalysis 8(3), 214-223.

Savalia, R. \& Chatterjee, S. (2017). Sensitive detection of brucine an anti-metastatic drug for hepatocellular carcinoma at carbon nanotubesnafion composite based biosensor. Biosensors and Bioelectronics 98, 371-377.

Saxena, U. \& Das, A. B. (2016). Nanomaterials towards fabrication of cholesterol biosensors: Key roles and design approaches. Biosensors and Bioelectronics 75, 196-205.

Sengiz, C., Congur, G., Eksin, E. \& Erdem, A. (2015). Multiwalled carbon nanotubes-chitosan modified single-use biosensors for electrochemical monitoring of drug-DNA interactions. Electroanalysis 27(8): 1855-1863.

Shanta, A. S., Al Mamun, K. A., Islam, S. K., McFarlane, N. \& Hensley, D. K. (2017). Carbon nanotubes, nanofibers and nanospikes for electrochemical sensing: A review. International Journal of High Speed Electronics and Systems 26(3). 1740008

Sharma, A., Kaushal, A. \& Kulshrestha, S. (2017). A Nano-Au/C-MWCNT based label free amperometric immunosensor for the detection of capsicum chlorosis virus in bell pepper. Archives of Virology 162(7), 2047-2052.

Shi, L., Wang, Y., Chu, Z., Yin, Y., Jiang, D., Luo, J., Ding, S. \& Jin, W. (2017). A highly sensitive and reusable electrochemical mercury biosensor based on tunable vertical single-walled carbon nanotubes and a target recycling strategy. Journal of Materials Chemistry B 5(5): 1073-1080.

Shiravand, T. and A. Azadbakht (2017). Impedimetric biosensor based on bimetallic AgPt nanoparticle-decorated carbon nanotubes as highly conductive film surface. Journal of Solid State Electrochemistry 21(6), 1699-1711.

Shoja, Y., Rafati, A. A. \& Ghodsi, J. (2017). Enzymatic biosensor based on entrapment of damino acid oxidase on gold nanofilm/MWCNTs nanocomposite modified glassy carbon electrode by sol-gel network: Analytical applications for d-alanine in human serum. Enzyme and Microbial Technology 100, 20-27.

Shoji, K., Akiyama, Y., Suzuki, M., Nakamura, N., Ohno, H. \& Morishima, K. (2016). Biofuel cell backpacked insect and its application to wireless sensing. Biosensors and Bioelectronics 78, 390395. 
Shrestha, B. K., Ahmad, R., Mousa, H. M., Kim, I. G., Kim, J. I. Neupane, M. P., Park, C. H. \& Kim, C. S. (2016). High-performance glucose biosensor based on chitosan-glucose oxidase immobilized polypyrrole/Nafion/functionalized multi-walled carbon nanotubes bio-nanohybrid film. Journal of Colloid and Interface Science 482, 39-47.

Shrivastava, S., Jadon. N. \& Jain, R. (2016). Nextgeneration polymer nanocomposite-based electrochemical sensors and biosensors: A review. TrAC - Trends in Analytical Chemistry 82, 55-67.

Shu, T., Gao, B., Yang, H., Su, L. \& Zhang, X. J., (2016). Horseradish Peroxidase-modified Single-walled Carbon Nanotubes as Biocathode for Assembling a Membrane-less GlucoseH2O2 Biofuel Cell. Current Nanoscience 12(4), 405-410.

Shuai, H. L., Wu, X., Huang, K. J. \& Zhai, Z. B. (2017). Ultrasensitive electrochemical biosensing platform based on spherical silicon dioxide/molybdenum selenide nanohybrids and triggered hybridization chain reaction. Biosensors and Bioelectronics 94, 616-625.

Shukla, S. K., Turner, A. P. F., \& Tiwari, A. (2015). Cholesterol oxidase functionalised polyaniline/carbon nanotube hybrids for an amperometric biosensor. Journal of Nanoscience and Nanotechnology 15(5), 33733377.

Singh, R., Mukherjee, M. D., Sumana, G., Gupta, R. K., Sood, S. \& Malhotra, B. D. (2014). Biosensors for pathogen detection: A smart approach towards clinical diagnosis. Sensors and Actuators B: Chemical 197, 385-404.

Soleymani, J. (2015). Advanced materials for optical sensing and biosensing of neurotransmitters. Trends in Analytical Chemistry 72, 27-44.

Somayeh, D., Mohammad, R., Khalil, A. \& Seyed, M. T. (2017). Recent nucleic acid based biosensors for Pb2+ detection. Sensors and Actuators B 246, 864-878.

Son, M., Kim, D., Park, K. S., Hong, S. \& Park, T. H. (2016). Detection of aquaporin-4 antibody using aquaporin-4 extracellular loop-based carbon nanotube biosensor for the diagnosis of neuromyelitis optica.Biosensors and Bioelectronics 78, 87-91.

Song, Y., Shen, Y., Gong, C., Chen, J., Xu, M., Wang, L. \& Wang, L. (2017). A Novel Glucose Biosensor Based on Tb@, Mesoporous MetalOrganic Frameworks/Carbon Nanotube Nanocomposites. ChemElectroChem 4(6), 1457-1462.

Su, Z., Xu, X., Xu, H., Zhang, Y., Li, C., Ma, Y., Song, D. \& Xie, Q. (2017). Amperometric thrombin aptasensor using a glassy carbon electrode modified with polyaniline and multiwalled carbon nanotubes tethered with a thiolated aptamer. Microchimica Acta 184(6), 1677-1682.

Sun, L., Liu, J., Zhang, P., Meng, Y., Liu, C., Ma, Y., Xie, Q. \& Meng, W. (2015). An amperometric biosensor and a biofuel cell of uric acid based on a chitosan/uricase-poly (furan-3-boronic acid)$\mathrm{Pd}$ nanoparticles/plated $\mathrm{Pd} /$ multiwalled carbon nanotubes/Au electrode. Journal of Electroanalytical Chemistry 739, 187-196.

Surucu, O. \& Abaci, S. (2017). Electrochemical and nonenzymatic glucose biosensor based on MDPA/MWNT/PGE nanocomposite. Materials Science and Engineering C 78, 539-545.

Syedmoradi, L., Daneshpour, M., Alvandipour, M., Gomez, F. A., Hajghassem, H. \& Omidfar, K. (2017). Point of care testing: The impact of nanotechnology. Biosensors and Bioelectronics 87, 373-387.

Szabó, T., R. Csekő, K. Hajdu, K. Nagy, O. Sipos, P. Galajda, G. Garab and L. Nagy (2017). Sensing photosynthetic herbicides in an electrochemical flow cell. Photosynthesis Research 132(2): 127-134.

Taei, M., Salavati, H., Hasanpour, F. \& Shafiei, A. (2016). Biosensor based on ds-DNA-decorated Fe $2 \mathrm{O}$ 3/SnO 2-chitosan modified multiwalled carbon nanotubes for biodetection of doxorubicin. IEEE Sensors Journal 16(1), 2431.

Tak, M., Gupta, V. \& Tomar, M. (2016). A ZnOCNT nanocomposite based electrochemical DNA biosensor for meningitis detection. $R S C$ Advances 6(80), 76214-76222.

Termehyousefi, A., Tanaka, H. \& Bagheri, S. (2017). Enhancement of glucose oxide electrontransfer mechanism in glucose biosensor via 
optimum physical chemistry of functionalized carbon nanotubes. Reviews in Chemical Engineering 33(2), 201-215.

Terse-Thakoor, T., Badhulika, S. \& Mulchandani, A. (2017). Graphene Oxide a Promising Material-A Review. Journal of Materials Research, 1-25.

Thandavan, K., Gandhi, S., Nesakumar, N., Sethuraman, S., Rayappan, J. B. B. \& Krishnan, U. M. (2015). Thandavan, K., Gandhi, S., Nesakumar, N., Sethuraman, S., Rayappan, J. B. B., \& Krishnan, U. M. (2015). Hydrogen peroxide biosensor utilizing a hybrid nano-interface of iron oxide nanoparticles and carbon nanotubes to assess the quality of milk. Sensors and Actuators B: Chemical 215, 166-173.

Thapa, A., Soares, A. C., Soares, J. C., Awan, I. T., Volpati, D., Melendez, M. E., Fregnani, J. H. T. G., Carvalho, A. L. \& Oliveira, O. N. (2017). Carbon nanotube matrix for highly sensitive biosensors to detect pancreatic cancer biomarker CA19-9. ACS Applied Materials and Interfaces 9(31), 25878-25886.

Thirumalraj, B., Palanisamy, S., Chen, S. M., Yang, C. Y., Periakaruppan, P. \& Lou, B. S. (2015). Direct electrochemistry of glucose oxidase and sensing of glucose at a glassy carbon electrode modified with a reduced graphene oxide/fullerene-C60 composite. RSC Advances 5(95): 77651-77657.

Tian, R., Chen, X., Liu, D. \& Yao, C. (2016). A Sensitive Biosensor for Determination of $\mathrm{Cu} 2+$ by One-step Electrodeposition.Electroanalysis 28(7), 1617-1624.

Tiwari, A. \& Turner, A. P. F. (Eds.). (2014). Biosensors nanotechnology. John Wiley \& Sons.Tiwari, J. N., Vij, V., Kemp, K. C. \& Kim, K. S. (2016). Engineered carbon-nanomaterialbased electrochemical sensors for biomolecules. ACS Nano 10(1), 46-80.

Unal, D. N., Eksin, E. \& Erdem, A. (2017). Carbon Nanotubes Modified Graphite Electrodes for Monitoring of Biointeraction Between 6Thioguanine and DNA. Electroanalysis, 29(10), 2292-2299.

Uwimbabazi, E., Mukasekuru, M. R. \& Sun, X. (2017). Glucose biosensor based on a glassy carbon electrode modified with multi-walled carbon nanotubes-chitosan for the determination of beef freshness. Food Analytical Methods 10(8), 2667-2676.

Van, T. V., Dung, P. T., Tam, L. T. \& Tam, P. D. (2014). Biosensor based on nanocomposite material for pathogenic virus detection.Colloids and Surfaces B: Biointerfaces 115, 176-181.

Vilian, A. T. E. \& Chen, S. M. (2014). Direct electrochemistry and electrocatalysis of glucose oxidase based poly (1-arginine)-multi-walled carbon nanotubes. RSC Advances 4(92), 5077150781.

Vilian, A. T. E., Chen, S. M., Kwak, C. H., Hwang, S. K., Huh, Y. S. \& Han, Y. K. (2016). Immobilization of hemoglobin on functionalized multi-walled carbon nanotubespoly-l-histidine-zinc oxide nanocomposites toward the detection of bromate and $\mathrm{H}_{2} \mathrm{O}_{2}$. Sensors and Actuators, B: Chemical 224: 607617.

Vilian, A. T. E., V. Veeramani, S. M. Chen, R. Madhu, C. H. Kwak, Y. S. Huh and Y. K. Han (2015). Immobilization of myoglobin on $\mathrm{Au}$ nanoparticle-decorated carbon nanotube/polytyramine composite as a mediator-free $\mathrm{H}_{2} \mathrm{O}_{2}$ and nitrite biosensor. Scientific reports, 5(1), 1-10.

Vinay D. P., Sravendra R., Hye J. Y. \& Chaurasiad, A. (2017). Progress in Polymer Science 67, 147.

Wahab, R., Khan, S. T., Ahmad, J., Ansari, S. G., Musarrat, J. \& Al-Khedhairy, A. A. (2016). Functionalization of anti-Brucella antibody on $\mathrm{ZnO}-\mathrm{NPs}$ and their deposition on aluminum sheet towards developing a sensor for the detection of Brucella. Vacuum, 146, 592-598.

Wang, B., Akiba, U. \& Anzai, J. I. (2017). Recent progress in nanomaterial-based electrochemical biosensors for cancer biomarkers: A review. Molecules 22(7), 1048.

Wang, L., Xiong, Q., Xiao, F. \& Duan, H. (2017). 2D nanomaterials based electrochemical biosensors for cancer diagnosis. Biosensors and Bioelectronics 89(1), 136-151.

Wang, M. Q., Zhang, Y., Bao, S. J., Yu. Y. N. \& Ye, C. (2016). Ni (II)-based metal-organic framework anchored on carbon nanotubes for 
highly sensitive non-enzymatic hydrogen peroxide sensing. Electrochimica Acta 190: 365-370.

Wang, Q., Q. Wang, K. Qi, T. Xue, C. Liu, W. Zheng and X. Cui (2015). In situ preparation of porous $\mathrm{Pd}$ nanotubes on a GCE for nonenzymatic electrochemical glucose sensors. Analytical Methods 7(20): 8605-8610.

Wang, W., Bao, T., Zeng, X., Xiong, H., Wen, W., Zhang, X. \& Wang, S. (2017). Ultrasensitive electrochemical DNA biosensor based on functionalized gold clusters/graphene nanohybrids coupling with exonuclease IIIaided cascade target recycling. Biosensors and Bioelectronics 91, 183-189.

Wang, X., Jiao, C., Wang, T. \& Yu, Z. (2016). Study on DNA damage induced by the reactive oxygen species generated in situ based on the multiwalled carbon nanotubes and hemoglobin. Journal of Electroanalytical Chemistry 767, 182-187.

Wang, Y., Li, T., Zhang, W. \& Huang, Y. (2014). A hydrogen peroxide biosensor with high stability based on gelatin-multiwalled carbon nanotubes modified glassy carbon electrode. Journal of Solid State Electrochemistry 18(7), 1981-1987.

Wang, Y., H. Sauriat-Dorizon, H. \& KorriYoussoufi, H (2017). Direct electrochemical DNA biosensor based on reduced graphene oxide and metalloporphyrin nanocomposite. Sensors and Actuators, B: Chemical 251, 40-48.

Wang, Z., Yu, J., Gui, R., Jin, H. \& Xia, Y. (2016). Carbon nanomaterials-based electrochemical aptasensors. Biosensors and Bioelectronics 79, 136-149.

Wei, C., X. Li, F. Xu, H. Tan, Z. Li, L. Sun and Y. Song (2014). Metal organic framework-derived

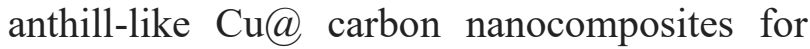
nonenzymatic glucose sensor. Analytical Methods 6(5), 1550-1557.

Wu, B., Hou, S., Miao, Z., Zhang, C. \& Ji, Y. (2015). Layer-by-layer self-assembling gold nanorods and glucose oxidase onto carbon nanotubes functionalized sol-gel matrix for an amperometric glucose biosensor. Nanomaterials 5(3), 1544-1555.

Wu, H., Huang, D., Jin, X., Luo, C., Dong, Q., Sun, B., Zong, R., Li, J., Zhang, L. \& Zhang, H.
(2016). Silver nanoparticles/polyethyleneimine/graphene oxide composite combined with surfactant film for construction of an electrochemical biosensor. Analytical Methods 8(14), 29612966.

Wu, J., He, J., Zhang, Y., Zhao, Y., Niu, Y. \& Yu, C. (2017). Thermal gradient for fluorometric optimization of droplet PCR in virtual reaction chambers. Microchimica Acta, 184(9), 34333439.

Wu, L., Lu, X., Fu, X., Wu, L. \& Liu, H. (2017). Gold nanoparticles dotted reduction graphene oxide nanocomposite based electrochemical aptasensor for selective, rapid, sensitive and congener-specific PCB77 detection. Scientific Reports 7(1). 1-7.

Wu, Q., Hou, Y., Zhang, M., Hou, X., Xu, L., Wang, N., Wang, J. \& Huang, W. (2016). Amperometric cholesterol biosensor based on zinc oxide films on a silver nanowire-graphene oxide modified electrode. Analytical Methods 8(8), 1806-1812.

Xia, H. Q., Kitazumi, Y., Shirai, O. \& Kano, K. (2017). Direct electron transfer-type bioelectrocatalysis of peroxidase at mesoporous carbon electrodes and its application for glucose determination based on bienzyme system. Analytical Sciences 33(7), 839-844.

Xu, J., Wang, Y. \& Hu, S. (2017). Nanocomposites of graphene and graphene oxides: synthesis, molecular functionalization and application in electrochemical sensors and biosensors. A review. Microchimica Acta 184(1), 1-44.

Xu, S., Qi, H., Zhou, S., Zhang, X. \& Zhang, C (2014). Mediatorless amperometric bienzyme glucose biosensor based on horseradish peroxidase and glucose oxidase cross-linked to multiwall carbon nanotubes. Microchimica Acta 181(5-6), 535-541.

Xu, S., Qin, X., Zhang, X. \& Zhang, C. (2015). A third-generation biosensor for hydrogen peroxide based on the immobilization of horseradish peroxidase on a disposable carbon nanotubes modified screen-printed electrode. Microchimica Acta 182(7-8), 1241-1246.

Xu, S. X., Li, J. L., Zhou, Z. L. \& Zhang, C. X. (2014). A third-generation hydrogen peroxide 
biosensor based on horseradish peroxidase immobilized by sol-gel thin film on a multi-wall carbon nanotube modified electrode. Analytical Methods 6(16), 6310-6315.

Xu, Z., Cheng, X., Tan, J. \& Gan, X. (2016). Fabrication of multiwalled carbon nanotubepolyaniline/platinum nanocomposite films toward improved performance for a cholesterol amperometric biosensor.Biotechnology and Applied Biochemistry 63(6), 757-764.

Yamada, K., Kim, C. T., Kim, J. H. Chung, J. H., Lee, H. G. \& Jun, S. (2014). Single walled carbon nanotube-based junction biosensor for detection of Escherichia coli. PLoS One, 9(9), p.e105767.

Yang, C., Denno, M. E., Pyakurel, P. \& Venton, B. J. (2015). Recent trends in carbon nanomaterialbased electrochemical sensors for biomolecules: A review. Analytica Chimica Acta, 887, 17-37.

Yang, C. Y., Chen, S. M. \& Palanisamy, S. (2016). Simultaneous electrochemical determination of dopamine, uric acid, tryptophan on electropolymerized aminothiazole and gold nanoparticles modified carbon nanotubes modified electrode. International Journal of Electrochemical Science 11(4), 2638-2649.

Yang, H., Gong, C., Miao, L. \& Xu, F. (2017). A glucose biosensor based on horseradish peroxidase and glucose oxidase co-entrapped in carbon nanotubes modified electrode. International Journal of Electrochemical Science 12(6), 4958-4969.

Yang, L., Liu, D., Cui, G. \& Xie, Y. (2017). Cu ${ }^{2+} 1$ $\mathrm{O} /$ graphene nanosheets supported on three dimensional copper foam for sensitive and efficient non-enzymatic detection of glucose. RSC Advances 7(31), 19312-19317.

Yang, M. \& Shimizu, T. (2017). Formation of Au nanoparticles on CNTs three dimensional structure for LSPR biosensor application In AIP Conference Proceedings 1817 (1), 020002. AIP Publishing LLC.

Yang, N., Chen, X., Ren, T., Zhang, P. \& Yang, D. (2015). Carbon nanotube based biosensors. Sensors and Actuators, B: Chemical 207, 690715.

Yardım, Y., Vandeput, M., Çelebi, M., Şentürk, Z. \& Kauffmann, J. M. (2017). A Reduced
Graphene Oxide-based Electrochemical DNA Biosensor for the Detection of Interaction between Cisplatin and DNA based on Guanine and Adenine Oxidation Signals.Electroanalysis 29(5), 1451-1458.

Yoo, M. S., Shin, M., Kim, Y., Jang, M., Choi, Y. E., Park, S. J., Choi, J., Lee, J. \& Park, C. (2017). Development of electrochemical biosensor for detection of pathogenic microorganism in Asian dust events. Chemosphere 175, 269-274.

Yu, H. W., Jiang, J. H., Zhang, Z., Wan, G. C., Liu, Z. Y., Chang, D. \& Pan, H. Z. (2017). Combining padlock exponential rolling circle amplification with $\mathrm{CoFe}_{2} \mathrm{O}_{4}$ magnetic nanoparticles for microRNA detection by nanoelectrocatalysis without a substrate. Analytical Biochemistry 519, 92-99.

Yu, N., Wang, Z., Wang, C., Han, J. \& Bu, H. (2017). Combining padlock exponential rolling circle amplification with $\mathrm{CoFe} 2 \mathrm{O} 4$ magnetic nanoparticles for microRNA detection by nanoelectrocatalysis without a substrate. Analytica Chimica Acta 962, 24-31.

Yu, Y., Chen, Z., He, S., Zhang, B., Li, X. \& Yao, M. (2014). Electrochemical evaluation of antioxidant capacity in pharmaceutical antioxidant excipient of drugs on guanine-based modified electrode. Biosensors and Bioelectronics 52: $147-152$.

Yue, Y., Zhihong, B., Sanming, L. \& Kun, Z. (2016). Electrochemical evaluation of antioxidant capacity in pharmaceutical antioxidant excipient of drugs on guanine-based modified electrode. Journal of Electroanalytical Chemistry 772, 58-65.

Zaidi, S. A. \& Shin, J. H. (2016). Recent developments in nanostructure based electrochemical glucose sensors. Talanta 149, 30-42.

Żelechowska, K.,Trawiński, B., Dramińska, S., Majdecka, D., Bilewicz, R. \& Kusz, B. (2017). Oxygen biosensor based on carbon nanotubes directly grown on graphitic substrate. Sensors and Actuators, B: Chemical 240, 1308-1313.

Zeng, Y., Zhu, Z., Du, D. \& Lin, Y. (2016). Nanomaterial-based electrochemical biosensors for food safety. Journal of Electroanalytical Chemistry 781, 147-154. 
Zhang, C., Song, H., Guo, W., Wu, H., Xu, X. \& Yan, S. (2016). Multi-Index Detection Electrochemical Biosensor Based on Graphene Aerogel/Platinum Nanoparticle Hybrid Materials. Journal of Bionanoscience 10(6), 495-500.

Zhang, J. \& Yuan, Z. (2016). Carbon nanomaterial based biosensors for onsite biomedical diagnosis. Nano biosensors for Personalized and onsite biomedical diagnosis: 567-582. Doi: 10.1049/PBHE001E_ch27

Zhang, R. \& Chen, W. (2017). Recent advances in graphene-based nanomaterials for fabricating electrochemical hydrogen peroxide sensors. Biosensors and Bioelectronics 89, 249-268.

Zhang, R., He, S., Zhang C. \& Chen, W. (2015). Three-dimensional Fe-and N-incorporated carbon structures as peroxidase mimics for fluorescence detection of hydrogen peroxide and glucose. Journal of Materials Chemistry $B$ $3(20), 4146-4154$.

Zhang, W. (2016). Application of Fe 3 O 4 nanoparticles functionalized carbon nanotubes for electrochemical sensing of DNA hybridization. Journal of Applied Electrochemistry 46(5), 559-566.

Zhang, W., Han, C., Jia, B., Saint, C., Nadagouda, M., Falaras, P., Sygellou, L., Vogiazi, V. \& Dionysiou, D. D. (2017). A 3D graphene-based biosensor as an early microcystin-LR screening tool in sources of drinking water supply. Electrochimica Acta 236, 319-327.

Zhang, X., Li, C. R., Wang, W. C., Xue, J., Huang, Y. L., Yang, X. X., Tan, B., Zhou, X. P., Shao, C., Ding, S. J. \& Qiu, J. F. (2016). A novel electrochemical immunosensor for highly sensitive detection of aflatoxin B1 in corn using single-walled carbon nanotubes/chitosan. Food Chemistry 192: 197-202.

Zhang, Y., Arugula, M. A., Kirsch, J. S., Yang, X., Olsen, E. \& Simonian, A. L. (2015). Layer-bylayer assembled carbon nanotubeacetylcholinesterase/biopolymer renewable interfaces: SPR and electrochemical characterization. Langmuir 31(4), 1462-1468.

Zhang, Y., Li, H., Chen, M., Fang, X., Pang, P., Wang, H., Wu, Z. \& Yang, W. (2017).
Ultrasensitive electrochemical biosensor for silver ion based on magnetic nanoparticles labeling with hybridization chain reaction amplification strategy. Sensors and Actuators B: Chemical 249, 431-438.

Zhang, Y., Liu, H., Yang, Z., Ji, S., Wang, J., Pang, P., Feng, L., Wang, H., Wu, Z. \& Yang, W. (2015). An acetylcholinesterase inhibition biosensor based on a reduced graphene oxide/silver nanocluster/chitosan nanocomposite for detection of organophosphorus pesticides. Analytical Methods 7(15), 6213-6219.

Zhao, C., Wu, X., Zhang, X., Li, P. \& Qian, X. (2017). Facile synthesis of layered $\mathrm{CuS} / \mathrm{RGO} / \mathrm{CuS}$ nanocomposite on $\mathrm{Cu}$ foam for ultrasensitive nonenzymatic detection of glucose. Journal of Electroanalytical Chemistry 785, 172-179.

Zhao, R., Liu, X., Zhang, J., Zhu, J. \& Wong, D. K. Y. (2015). Enhancing direct electron transfer of glucose oxidase using a gold nanoparticle| titanate nanotube nanocomposite on a biosensor. Electrochimica Acta 163, 64-70.

Zhao, Y., Huo, D., Bao, J., Yang, M., Chen, M., Hou, J., Fa, H. \& Hou, C. (2017). Biosensor based on 3D graphene-supported $\mathrm{Fe}_{3} \mathrm{O}_{4}$ quantum dots as biomimetic enzyme for in situ detection of $\mathrm{H}_{2} \mathrm{O}_{2}$ released from living cells. Sensors and Actuators, B: Chemical 244, 1037-1044.

Zheng, Y., Liu, Z., Zhan, H., Li, J. \& Zhang, C. (2016). Studies on electrochemical organophosphate pesticide (OP) biosensor design based on ionic liquid functionalized

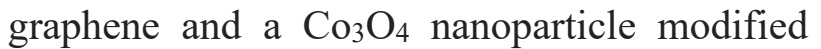
electrode. Analytical Methods 8(26), 5288-5295.

Zhiyang, L., Fan, G. \& Zhiyong. G. (2017). Vertically aligned $\mathrm{Pt}$ nanowire array/Au nanoparticle hybrid structure as highly sensitive amperometric biosensors. Sensors and Actuators B 243, 1092-1101.

Zhou, J., Li, H., Yang, H., Cheng, H. \& Lai, G. (2017). Immobilization of glucose oxidase on a carbon nanotubes/dendrimer-ferrocene modified electrode for reagentless glucose biosensing. Journal of Nanoscience and Nanotechnology 17(1), 212-216. 
Zhu, C., Du, D. \& Lin, Y. (2017). Graphene-like 2D nanomaterial-based biointerfaces for biosensing applications. Biosensors and Bioelectronics 89: 43-55.

Zhu, G. \& Lee, H. J. (2017). Electrochemical sandwich-type bi osensors for $\alpha-1$ antitrypsin with carbon nanotubes and alkaline phosphatase labelled antibody-silver nanoparticles. Biosensors and Bioelectronics 89, 959-963.

Zhu, J., Huo, X., Liu, X. \& Ju, H. (2016). Gold nanoparticles deposited polyaniline-TiO2 nanotube for surface plasmon resonance enhanced photoelectrochemical biosensing. ACS Applied Materials and Interfaces 8(1), 341349.

Zhu, J., Wu, X. Y., Shan, D., Yuan, P. X. \& Zhang, X. J. (2014). Sensitive electrochemical detection of NADH and ethanol at low potential based on pyrocatechol violet electrodeposited on single walled carbon nanotubes-modified pencil graphite Talanta 130, 96-102.

Zhu, X., Wu, G., Lu, N., Yuan, X. \& Li, B. (2017).

A miniaturized electrochemical toxicity biosensor based on graphene oxide quantum dots/carboxylated carbon nanotubes for assessment of priority pollutants. Journal of
Hazardous Materials 324, 272-280.

Zhu, Y., Lu, S., Manohari, A. G., Dong, X., Chen, F., Xu, W., Shi, Z. \& Xu, C. (2017). Polydopamine interconnected graphene quantum dots and gold nanoparticles for enzymeless $\mathrm{H}_{2} \mathrm{O}_{2}$ detection. Journal of Electroanalytical Chemistry 796, 75-81.

Zhu, Z. (2017). An Overview of Carbon Nanotubes and Graphene for Biosensing Applications. Nano-Micro Letters 9 (3), 1-24.

Zhuang, X., Tian, C., Luan, F., Wu, X. \& Chen, L. (2016). One-step electrochemical fabrication of a nickel oxide nanoparticle/polyaniline nanowire/graphene oxide hybrid on a glassy carbon electrode for use as a non-enzymatic glucose biosensor RSC Advances 6(95), 9254192546.

Zribi, B., Roy, E., Pallandre, A., Chebil, S., Koubaa, M., Mejri, N., Magdinier G. H., Sola, C., Korri-Youssoufi, H. \& Haghiri-Gosnet, A. M. (2016). A microfluidic electrochemical biosensor based on multiwall carbon nanotube/ferrocene for genomic DNA detection of Mycobacterium tuberculosis in clinical isolates Biomicrofluidics 10(1). DOI: 10.1063/1.4940887 